\title{
Specialization in a Nitrogen-Fixing Symbiosis: Proteome Differences Between Sinorhizobium medicae Bacteria and Bacteroids
}

\author{
Svetlana N. Yurgel, ${ }^{1,2, \dagger}$ Yi Qu, ${ }^{3}$ Jennifer T. Rice ${ }^{2}$, Nivethika Ajeethan, ${ }^{1,4}$ Erika M. Zink, ${ }^{3}$ Joseph M. Brown, ${ }^{3}$ \\ Sam Purvine, ${ }^{5}$ Mary S. Lipton, ${ }^{3}$ and Michael L. Kahn ${ }^{2,6}$ \\ ${ }^{1}$ Department of Plant, Food and Environmental Sciences, Faculty of Agriculture, Dalhousie University, P.O. Box 550, Truro, \\ Nova Scotia, B2N 5E3, Canada \\ ${ }^{2}$ Institute of Biological Chemistry, Washington State University, Pullman, WA 99164-6340, U.S.A. \\ ${ }^{3}$ Biological Sciences Division, Pacific Northwest National Laboratory, Richland, WA 99352, U.S.A. \\ ${ }^{4}$ Faculty of Technology, University of Jaffna, Sri Lanka \\ ${ }^{5}$ Environmental Molecular Sciences Division, Pacific Northwest National Laboratory, Richland, WA 99352, U.S.A. \\ ${ }^{6}$ School of Molecular Biosciences, Washington State University, Pullman, WA 99164-6340, U.S.A.
}

Accepted 11 August 2021.

Using tandem mass spectrometry (MS/MS), we analyzed the proteome of Sinorhizobium medicae WSM419 growing as free-living cells and in symbiosis with Medicago truncatula. In all, 3,215 proteins were identified, over half of the open reading frames predicted from the genomic sequence. The abundance of 1,361 proteins displayed strong lifestyle bias. In total, 1,131 proteins had similar levels in bacteroids and free-living cells, and the low levels of 723 proteins prevented statistically significant assignments. Nitrogenase subunits comprised approximately $12 \%$ of quantified bacteroid proteins. Other major bacteroid proteins included symbiosisspecific cytochromes and FixABCX, which transfer electrons to nitrogenase. Bacteroids had normal levels of proteins involved in amino acid biosynthesis, glycolysis or gluconeogenesis, and the pentose phosphate pathway; however, several amino acid degradation pathways were repressed. This suggests that bacteroids maintain a relatively independent anabolic metabolism. Tricarboxylic acid cycle proteins were highly expressed in bacteroids and no other catabolic pathway emerged as an obvious candidate to supply energy and

\section{${ }^{\dagger}$ Corresponding author: S. Yurgel; syurgel@dal.ca}

Funding: This material is based upon work supported by the United States Department of Energy (DOE), Office of Science, Office of Energy Physical Biosciences Program, under award number DE-FG0396ER20225. This work was supported by the Agricultural Research Center at Washington State University in association with United States Department of Agriculture-National Institute of Food and Agriculture projects NP00773 and WNP00008. Portions of this research were supported by the DOE Office of Biological, Environmental Research Genome Sciences Program under the Pan-Omics project and Discovery Grant from the Natural Sciences and Engineering Research Council of Canada grant EGP 485260. The proteomic analysis was performed in the Environmental Molecular Science Laboratory, a DOE National Scientific User facility at Pacific Northwest National Laboratory in Richland, WA.

*The $\boldsymbol{e}$-Xtra logo stands for "electronic extra" and indicates that supplementary figures and supplementary tables are published online.

The author(s) declare no conflict of interest. distributed under the CC BY-NC-ND 4.0 International license. reductant to nitrogen fixation. Bacterial stress response proteins were induced in bacteroids. Many WSM419 proteins that are not encoded in $S$. meliloti $R \mathbf{R m 1 0 2 1}$ were detected, and understanding the functions of these proteins might clarify why $S$. medicae WSM419 forms a more effective symbiosis with $M$. truncatula than $S$. meliloti $\mathrm{Rm} 1021$.

Keywords: bacteria-plant interaction, bacteroids, flavoproteins, microaerobic metabolism, nitrogen fixation, Sinorhizobium-Medicago truncatula symbiosis, sustainable agriculture, tandem mass spectrometry

Rhizobium-legume associations are the largest contributor to terrestrial biological dinitrogen $\left(\mathrm{N}_{2}\right)$ fixation and a critical part of nitrogen cycling in the biosphere (Herridge et al. 2008). Legumes gain access to the enormous atmospheric $\mathrm{N}_{2}$ resource by establishing a symbiotic association with soil $\alpha$ - and $\beta$-proteobacteria, generally called rhizobia. This gives legumes a significant competitive advantage in nitrogen-limiting environments and makes the Rhizobium-legume symbiosis an important part of organic and sustainable agriculture. Substantial effort has been made to understand the mechanisms controlling the efficiency of $\mathrm{N}_{2}$-fixing Rhizobium-legume symbioses (Kazmierczak et al. 2017; Terpolilli et al. 2012). The core of efficiency of $\mathrm{N}_{2}$ fixation lies in the strong coordination between the plant and bacteria mediated by signal exchange during recognition and infection processes (Oldroyd et al. 2011), as well as in coregulation of micro- and macrosymbiotic development and nutrient exchange (Terpolilli et al. 2012, Udvardi and Poole 2013).

$\mathrm{N}_{2}$-fixing root nodules are plant-derived organs in which a large number of the plant cells are infected with a symbiotic form of rhizobia, also known as bacteroids (Haag et al. 2012). In some Rhizobium-legume associations, especially in those producing indeterminate nodules, bacterial differentiation shuts down most aspects of cell growth and division and leads to changes in cell-wall composition and increased DNA content in mature bacteroids (Terpolilli et al. 2012). The host plant can control the irreversible (terminal) bacteroid differentiation by production of nodule-specific cysteine-rich (NCR) peptides that are targeted to the bacteria and enter the bacterial membrane and cytosol (Van de Velde et al. 2010). Mature bacteroids express the $\mathrm{N}_{2}$-fixing apparatus (nif and fix genes) required to 
reduce atmospheric $\mathrm{N}_{2}$ to ammonia and inhibit ammonia assimilation into amino acids (Patriarca et al. 2002). In general, legumes provide bacteroids with a broad spectrum of inorganic ions and organic compounds, including dicarboxylic acids (Udvardi and Poole 2013; Yurgel and Kahn 2004), while the bacteria fix $\mathrm{N}_{2}$ and provide fixed nitrogen to the plants for growth. It has been reported that bacteroids in the Rhizobium leguminosarum-pea symbiosis do not synthesize adequate levels of branched-chain amino acids (Bra) to allow nitrogen fixation to occur and rely on the plant to supply these amino acids (Prell et al. 2009; Terpolilli et al. 2012). Despite the fact that dicarboxylic acids were shown to be the major carbon source for $\mathrm{N}_{2}$-fixing bacteroids, large quantities of sugars are found in nodules (Streeter 1980), suggesting that they have a role in nodule metabolism and $\mathrm{N}_{2}$ fixation.

With genome sequences available for both symbiotic partners (Galibert et al. 2001; Young et al. 2011), Sinorhizobium meliloti Rm1021-Medicago truncatula Jemalong A17 has become a model system for studying the beneficial interaction between plant and bacteria. A comparative genomic study of 48 Sinorhizobium strains was recently published (Sugawara et al. 2013). Transcriptomics and proteomics approaches have been carried out to study coregulation of plant and bacteria metabolism in this system, as well as in the number of other symbiotic associations (Barnett et al. 2004; Capela et al. 2006; Delmotte et al. 2010; Djordjevic 2004; Gokulakannan and Niehaus 2010; Gomes et al. 2012a, b; Koch et al. 2010; Larrainzar et al. 2007; Limpens et al. 2013; Maunoury et al. 2010; Marx et al. 2016; Moreau et al. 2011; Natera et al. 2000; Resendis-Antonio et al. 2012; Salavati et al. 2012; Schenkluhn et al. 2010; Sobrero et al. 2012; Stacey et al. 2006; Volkening et al. 2012).

Advances in tandem mass spectrometry (MS/MS) and bioinformatics allows "sequencing" of proteomes by determining the peptides produced after trypsin digestion followed by matching these peptides to peptides predicted from in silico digests of protein sequences derived from the genomic DNA sequences (Delmotte et al. 2010; Koch et al. 2010). However, with exception of a recently published study (Marx et al. 2016), despite the close interconnection between the macro- and microsymbiont, the studies of symbiosis have not involved the analysis of a global proteome of microsymbiont located directly inside the plant nodules. Critical for a two-organism interaction, the separation of the distinct proteomes can be done computationally instead of by physical separation of the tissues. This approach was used to study the free-living and symbiotic proteomes of Mesorhizobium loti (Tatsukami et al. 2013). A zone-specific proteome and metabolome of Medicago truncatula-S. medicae strain WSM419 symbiosis has been published (Ogden et al. 2017). In the experiments presented here, we used the highly efficient $S$. medicae strain WSM419 (Reeve et al. 2010) instead of $S$. meliloti Rm1021, which does not perform very well during infection and nitrogen fixation in association with $M$. truncatula A17 (Simsek et al. 2007; Terpolilli et al. 2008). S. meliloti and $S$. medicae are closely related, with predicted proteins generally having greater than $93 \%$ identity at the amino acid level (Reeve et al. 2010). However, in contrast to the study conducted by Ogden et al. (2017), which focused on the differences between stages of nodule development in the $M$. truncatula-S. medicae symbiosis, our study addresses in much greater detail the transformation from free-living bacteria to symbiotic bacteroids.

In all, 3,215 bacterial proteins were identified in this study in free-living or symbiotic proteomes. In the free-living bacteria, we observed approximately $47 \%$ of the total number of proteins predicted from the genome sequence, while only $26 \%$ of the predicted proteins were found in the symbiotic $S$. medicae proteome. This difference is likely due to the greater proportion of bacterial material available from free-living bacteria, because the symbiotic proteome also contained plant material. In this work, we compared the free-living and symbiotic proteomes of $S$. medicae in order to gain a better idea of the physiological changes that accompany the differentiation of free-living rhizobia to bacteroids. This gave us a good view of the metabolic capabilities in the two states; however, many regulatory proteins were either below the level of detection or absent.

\section{RESULTS AND DISCUSSION}

\section{S. medicae proteome.}

In total, 145,220 peptides derived from 3,215 bacterial proteins were identified in free-living or symbiotic proteomes (Supplementary Table S1), which was approximately $48.7 \%$ of the predicted coding capacity of the $S$. medicae WSM419 genome (Reeve et al. 2010). Specifically, 3,119 and 1,728 bacterial proteins were detected in free-living cell extracts and in wholenodule extracts without bacteroid isolation, respectively. In total, 1,487 and 96 proteins were found only in free-living cells or in symbiosis, respectively. More than 25,000 peptides derived from approximately 5,000 plant proteins were also identified in nodule tissues; this information is included as Supplementary Table S2 but not analyzed further.

Principal component analysis indicated significant differences in protein profiles between free-living and symbiotic forms of $S$. medicae and the consistency between biological replicates (Fig. $1)$. When the free-living and symbiotic protein levels were compared quantitatively by applying the $\beta$-binominal test to the values of the spectral counts, which were used as an index of protein abundance, 1,361 proteins displayed significantly different abundance in the two proteomes (more than twofold difference, $P<0.01$ ). In all, 199 proteins were significantly more abundant in symbiosis compared with free-living cells (symbiosis-specific proteins, Supplementary Table S3), 1,162 proteins were significantly more abundant in free-living cells compared with symbiosis (free-living-specific proteins, Supplementary Table S4), and 1,132 were not significantly different (generalfunction proteins, Supplementary Table S5). Additionally, because their spectral counts were low (spectral count $<3$, averaged from three biological replicates), 723 proteins could not be assessed to have statistically significantly higher abundance in symbiosis or in free-living cells. Consequently, these proteins were classified as low count (Supplementary Table S6) and were excluded from our further analysis (Fig. 2). Nevertheless, the fact that some of these proteins were found only in one proteome but not in another suggests that at least some of these are, indeed, lifestyle specific. Although these comparisons may be somewhat biased by the use of a simple medium in growing the free-living cells, the presence of many biosynthetic pathways in bacteroids (below) suggests that this is not a major issue. The results are consistent with previous work showing that free-living Sinorhizobium cells employ a much broader range of cell processes than are used in symbiosis (Udvardi and Poole 2013).

\section{Cluster of orthologous group functional categories of $S$. medicae proteins.}

WSM419 proteins have been classified into 20 recognized Clusters of Orthologous Genes (COG) functional categories (Reeve et al. 2010). Pearson's $\chi^{2}$ test $(P<0.01)$ showed that there were significant differences between the functional profile of symbiosis-specific and free-living-specific proteins, as well as symbiosis-specific and general-function proteins. On the other hand, no significant differences were detected between the functional profiles of free-living-specific and general-function proteins. Additionally, the functional profiles of the free-living-specific and general-function proteins were not different from the global 
functional profile of $S$. medicae. We used Fisher's test with multiple testing correction to identify COG functional categories that were overrepresented or underrepresented in lifestylespecific proteomes. The number of genes or proteins annotated as "Posttranslational modification, protein turnover, chaperones" was the only significantly overrepresented group (adjusted $P$ value $<0.006$ ) in the nodule-specific proteome (Fig. 3).

\section{WSM419 Kyoto Encyclopedia of Genes and \\ Genomes pathways.}

In total, 1,586 $S$. medicae genes were assigned to metabolic enzymes (Reeve et al. 2010). We sorted the identified proteins onto $S$. medicae pathways using the Kyoto Encyclopedia of Genes and Genomes (KEGG) scheme. The free-living and symbiotic proteomes included 1,330 of these KEGG annotated enzymes, or $83 \%$ of all enzymes covered by the KEGG annotation. Therefore, at this depth, the proteome should give a fairly accurate profile of the metabolic capabilities of the bacteria. In all, 81\% (676 enzymes), 85\% (274 enzymes), and 79\% (239 enzymes) of all proteins belonging to $S$. medicae "Metabolic pathways", "Biosynthesis of secondary metabolites", and "Microbial metabolism in diverse environments", respectively, were found in either the free-living or nodule proteomes. Enzymes belonging to 106 metabolic pathways were identified (Supplementary Table S7). In addition, we were able to identify a significant number of regulatory proteins, which tend to be less abundant than metabolic proteins. For example, we detected $56 \%$ of the predicted two-component regulatory system proteins in the KEGG database (Supplementary Table S7; Supplementary

\section{Total protein detected (Total 3215)}

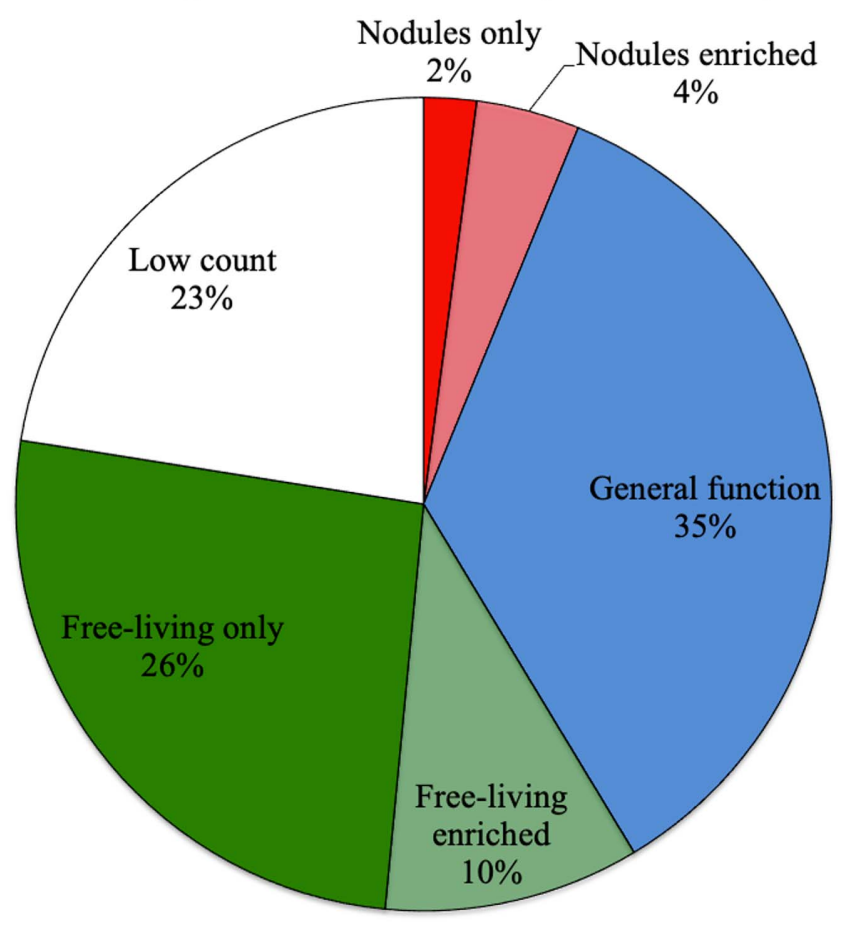

Fig. 2. Lifestyle distribution of the proteins identified in the study.

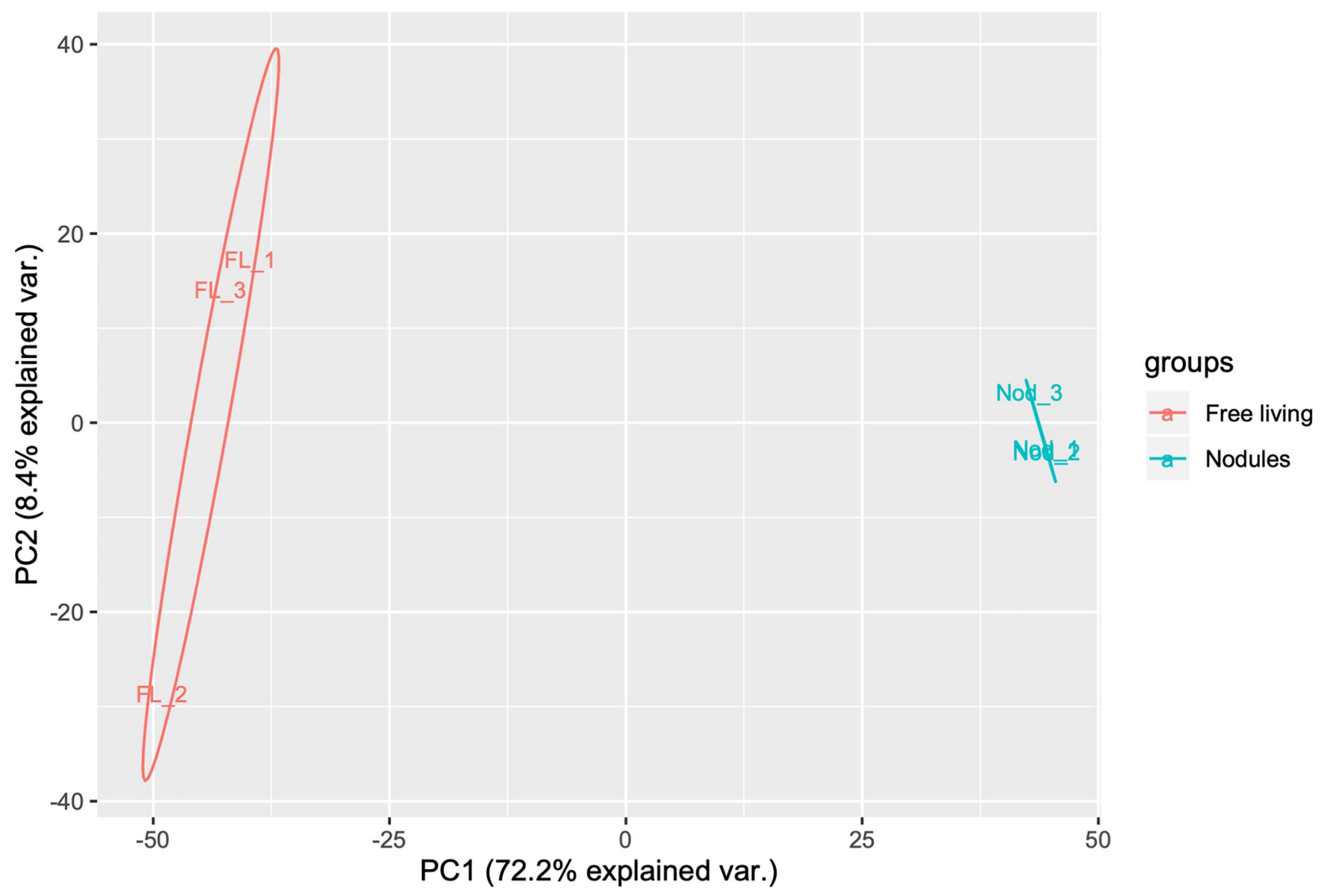

Fig. 1. Multivariate analysis. Score plot results from principal component (PC) analysis using protein profiles of free-living and symbiotic forms of Sinorhizobium medicae. 
Fig. S1.1). We used Fisher's test with multiple testing correction to identify KEGG pathways with altered representation $(P<$ $0.05)$ between the two conditions. ABC transporters were underrepresented in the total, free-living-specific and general-function proteomes. Two-component systems were underrepresented in the general-function proteome. Aminoacyl-transfer RNA synthetases were underrepresented in total and free-living-specific proteomes. Bacterial secretion systems and flagellar assembly proteins were underrepresented in the total proteome. On the other hand, tricarboxylic acid (TCA) or citric acid cycle proteins were overrepresented in the symbiosis-specific proteome.

When annotated enzymes were mapped onto KEGG pathways, in some cases more than one homolog of the same enzyme was identified. These homologs had distinct lifestyle specificity. As an example, there is differential production of three dihydrolipoamide dehydrogenases: a free-living-specific form, LpdA3/Smed_2829, and two symbiosis-specific forms, LpdA2/Smed_2936 and LpdA1/Smed_1081. LpdA proteins function as a component of the $\alpha$-ketoglutarate, pyruvate, and Bra-dehydrogenase complexes and of the glycine cleavage system, suggesting specific roles for the LpdA homologs in $S$. medicae. Detailed maps of the major WSM419 KEGG pathways populated with enzymes identified in the study are shown in Supplementary Fig. S1, with different colors showing the expression pattern of these enzymes. A schematic representation of some findings is shown in Figure 4.

\section{$\mathbf{N}_{2}$ fixation.}

The specific proteins discussed in this article are listed in Supplementary Table S8. As expected, NifH/Smed_6225, NifD/ Smed_6224, and NifK/Smed_6223 were the most abundant proteins in the nodule-derived bacterial proteome, comprising approximately $12 \%$ of the peptides detected (approximately 25,000 of the normalized approximately 200,000 peptides) (Supplementary Tables S1 and S2). NifD, NifK, and NifH were detected at a low level in the free-living proteome. In the nodule proteome, the nitrogenase $\mathrm{Fe}-\mathrm{Mo}$ cofactor biosynthesis proteins NifN/Smed_6181 and NifB/Smed_6233, iron-molybdenum cluster-binding protein NifX/Smed_6211, nitrogenase molybdenumcofactor synthesis protein NifE/Smed_6222, and transcriptional

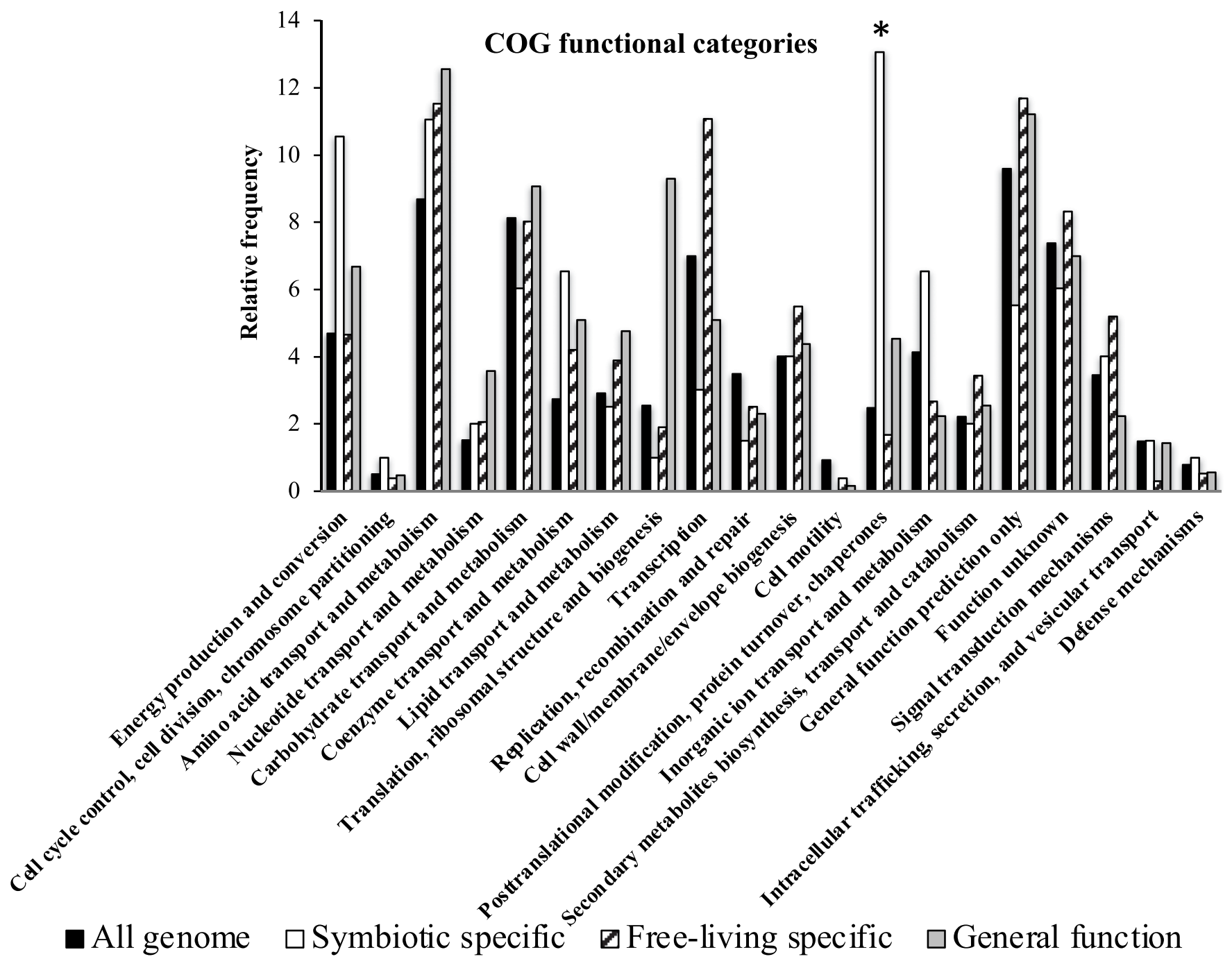

Fig. 3. Cluster of orthologous group (COG) functional categories. Relative frequency of the proteins is given for four data sets: (i) all Sinorhizobium medicae protein-coding genes, (ii) symbiosis-specific proteins $(n=199)$, (iii) free-living-specific proteins $(n=1,162)$, and (iv) general-function proteins $(n=1,131)$. Relative frequencies were calculated as percent proteins present in each category from total number of proteins in the data set. The number of symbiosis-specific proteins is likely to have been underestimated because these were analyzed in the presence of the plant nodule proteins. Asterisks indicate statistical significance for overrepresented or underrepresented proteins in a given category, which was computed using the Fisher's test with multiple testing correction (adjusted $P$ value $<0.01$ ). 
activator NifA/Smed_6231 were significantly increased in relative abundance. Ferredoxin Smed_6219 (FdxB in S. meliloti Rm1021), electron-transfer flavoproteins FixA/Smed_6228 and FixB/Smed_6229, as well as the linked oxidoreductase FixC/ Smed_6230 and the ferredoxin-like FixX/Smed_6231 protein were highly abundant in the nodules and absent from the freeliving cells. It has been suggested that FixABCX proteins act together to transfer electrons to nitrogenase (Earl et al. 1987) and serve as the alternative entry point for low-potential (highenergy) electrons from NADH (Buckel and Thauer 2018; Ledbetter et al. 2017). Based on transposon sequencing analysis, the fix $A B C X$ complex was found to be one of the "top-ranked symbiosis genes" in S. meliloti (Flores-Tinoco et al. 2020). $\sigma-54$ RNA polymerase initiation factor RpoN/Smed_0015 and subunits of the symbiotically essential $c b b_{3}$-type cytochrome oxidases FixP/Smed_6265, FixO/Smed_6267, and FixN/Smed_5935 were part of the nodule-specific proteome (Supplementary Table S4). Upregulation of NifHDK, Fdx, $c b b_{3}$ cytochrome oxidase, and RpoN was also detected in other studies (Becker et al. 2004; Djordjevic et al. 2003). Surprisingly, a low level of another cytochrome $c$ oxidase subunit homolog, FixO/Smed_5925, was found only in the free-living proteome (Supplementary Table S4; Supplementary Fig. S1.2). The FixJ/Smed_6273 response regulator was found equally present in both the free-living and symbiotic proteomes (Supplementary Table S5).
Shock adaptation: DNA replication, transcription, ribosomal structure and biogenesis, and translation.

Our data did not show strong evidence that DNA replication, translation, or ribosomal structure and biogenesis decreased in abundance during symbiosis (Supplementary Fig. S1.3-5). However, proteins involved in DNA repair such as homologous recombination (Supplementary Fig. S1.6), nucleotide excision repair (Supplementary Fig. S1.7), mismatch repair (Supplementary Fig. S1.8), and base excision repair (Supplementary Fig. S1.9) were decreased in abundance during symbiosis. Additionally, proteins involved in protein synthesis and stress adaptation such as heat shock chaperones DnaK/Smed_3389, HslV/ Smed_3264, IbpA/Smed_2715, Hsp20/Smed_4626, and Hsp20/ Smed_0049; general chaperones GroEL1/Smed_0408, GroES3/ Smed_1282, GroEL3/Smed_2181, GroEL4/Smed_4130, and GroEL5/Smed_6084; and trigger factor Tig/Smed_1181 were highly induced in symbiosis (Supplementary Table S7; Supplementary Fig. S1.10). As in in Bradyrhizobium japonicum (Delmotte et al. 2010), the ATP-dependent proteases Lon/ Smed_0874 and ClpB/Smed_2499 increased in abundance during symbiosis.

Anti- $\sigma$ factor RsiA1/Smed_2346 was classified as a generalfunction protein whereas anti-anti- $\sigma$ factor RsiB1/Smed_2347 was classified as a symbiosis-specific protein. In S. meliloti, two homologous anti- $\sigma$ factors, RsiA1 and RsiA2, target the general

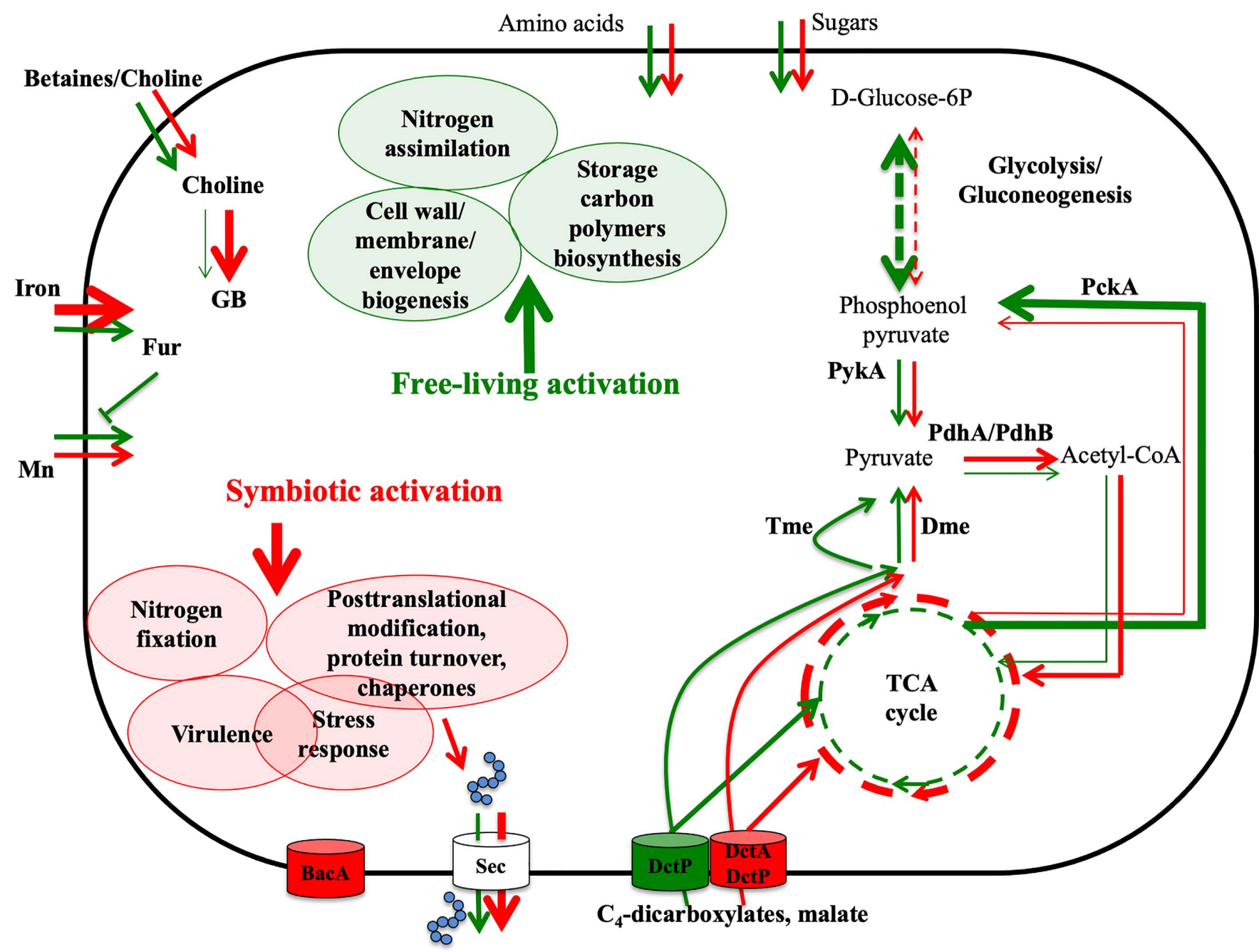

Fig. 4. Visualization of global changes in bacteroid metabolism. Green-filled ellipses represent processes abundantly present in free-living cells. Redfilled ellipses represent processes overactive in symbiosis. Green arrows represent processes or reactions found in free-living cells. Red arrows represent processes or reactions found in symbiosis. Weights of the arrows indicate relative activity of the processes or reactions. 
stress-response regulator RpoE2 (Bastiat et al. 2010; Sauviac et al. 2007). Additionally, in response to stress, two redundant homologous PhyR-type response regulators, RsiB1 and RsiB2, interact with the anti- $\sigma$ factors to relieve RpoE2 inhibition caused by RsiA1 and RsiA2 (Bastiat et al. 2010). RpoE2 itself was detected as a low-abundance protein. It has been shown that $B$. japonicum RpoE2 is involved in the symbiotic interaction with host plants (Gourion et al. 2009), whereas no such role was observed in S. meliloti (Sauviac et al. 2007). In this study, $S$. medicae free-living cells were grown at the same temperature in the same growth chamber that was used for growing the plants; thus, it is unlikely that the differences in stress-related protein expression between free-living and symbiotic forms of $S$. medicae were due to temperature stress, which implies that other forms of stress in bacteroids were leading to the observed changes. Transcriptomic and proteomic analysis of $S$. meliloti and $B$. japonicum symbiosis also revealed an activation of stress responses in bacteroids (Becker et al. 2004; Delmotte et al. 2010).

Like $S$. meliloti (Bittner et al. 2007), the $S$. medicae genome contains five loci encoding GroEL chaperones or their GroES cochaperones (Reeve et al. 2010). In S. meliloti, groESL1 encodes the housekeeping GroEL/GroES chaperone and is highly expressed in both symbiotic and free-living cells, while groESL5 is specialized for stress responses (Bittner et al. 2007). The roles of the other GroE proteins are still unclear. With the exception of GroES3/Smed_1282, which was found only in the nodule proteome, all other GroE chaperones were detected in both freeliving and nodule proteomes. GroEL/Smed_0408, which is most similar to $S$. meliloti housekeeping GroEL1, was the most abundant GroE in both proteomes and was statistically overproduced in symbiosis (Bittner et al. 2007). In S. meliloti, GroEL1 is required for efficient infection, terminal differentiation, and nitrogen fixation and can form complexes with the $M$. truncatula nodule-specific cysteine-rich peptide NCR247 (Farkas et al. 2014). GroEL1 cochaperone GroES/Smed_0409 was classified as a general-function protein. In S. meliloti, GroES and GroEL isoforms were found in both free-living and symbiotic proteomes (Djordjevic et al. 2003; Moreau et al. 2011; Natera et al. 2000).

The pattern of the expression of the CspA cold-shock protein was very interesting. CspA4/Smed_1620 was among the 20 most abundant symbiotic proteins. CspA3/Smed_2238 and CspA2/Smed_5421 were the only free-living-specific stressresponse proteins. CspA8/Smed_5162, CspA7/Smed_2874, CspA6/Smed_6064, CspA5/Smed_1449, CspA/Smed_2005, and CspA1/Smed_1949 were annotated as general-function proteins, suggesting distinct roles for specific CspA proteins in free-living and symbiotic lifestyles of Sinorhizobium. Transcriptional data suggest that there is distinct compartmentalization of some of the CspA proteins (Roux et al. 2014). Further work has been done in our laboratory on the CspA proteins (J. P. Price, X. Liu, S. N. Yurgel, and M. L. Kahn, unpublished data)

The BacA/Smed_4510 membrane protein is essential for establishing prolonged intracellular infections (LeVier et al. 2000). The BacA ABC VLCFA exporter is involved in bacteroid envelopment (Ferguson et al. 2002) and is essential for protecting $S$. meliloti against the antimicrobial activities of host NCR peptides in free-living cells and in symbiosis (Haag et al. 2011). We were able to detect a relatively low level of BacA only in symbiosis. This might indicate that, in contrast to $S$. meliloti, BacA protein is not produced in free-living $S$. medicae cells or is made at a level below our detection capability. An analysis of the response of an $S$. medicae bacA mutant to NCR peptide treatment might clarify this question. For example, if BacA is still produced in $S$. medicae and performs a similar function as in $S$. meliloti, the $S$. medicae bacA mutant should exhibit more sensitivity to host NCR peptides compared with the wild-type strain.

NerA/Smed_1245 was very highly induced in symbiosis. This protein was previously identified as a nodule-specific Rm1021 protein (Djordjevic 2004). NerA is annotated as a glycerol trinitrate (GTN) reductase, an assignment that is based on very strong homology to the nerA gene from Agrobacterium radiobacter, in which it was shown that NerA encodes a GTN reductase and enables $A$. radiobacter to use GTN and related explosives as nitrogen sources (Marshall et al. 2004; White et al. 1996). NerA is a flavoprotein oxidoreductase from a group known as Old Yellow Enzymes (OYEs). OYEs catalyze various redox reactions (Williams and Bruce 2002) but very little is known about their physiological roles. In $S$. medicae nodules, NerA is probably not involved in GTN metabolism because GTN is unlikely to be present. On the other hand, recent studies suggested a role for OYE in oxidative stress responses (Fitzpatrick et al. 2003; Haarer and Amberg 2004; Kitzing et al. 2005). For example, exposure to hydrogen peroxide induced the expression of the OYE YqjM protein is Bacillus subtilis (Fitzpatrick et al. 2003).

Rm1021 has a homolog of the $S$. medicae WSM419 nerA gene, Smc01227 (94\% identity). When nerA (Smc01227) was deleted from Rm1021, the resulting mutant became more sensitive to hydrogen peroxide (Supplementary Fig. S2), confirming a role for NerA in the adaptation of Sinorhizobium to oxidative stress. However, our data show that NerA was not essential in establishing an effective symbiosis between Rm1021 and alfalfa. Similarly, NerA was not essential for establishing an effective symbiosis between Rm1021 and $M$. truncatula or between WSM419 and either $M$. truncatula or alfalfa plants. When Smed_1245 or Smc01227 were deleted from WSM419 or Rm1021, respectively, the resulting mutants (WSM419AnerA and $\operatorname{Rm} 1021 \Delta$ nerA) formed healthy pink nodules on alfalfa and $M$. truncatula roots. Both host plants nodulated with the nerA mutants were green and their biomass was similar to that of the plants nodulated with the corresponding wild-type strain (Supplementary Fig. S3). Another bacteroid protein related to the oxidative stress response in nodules is KatA/Smed_0327, which has catalase or peroxidase activities. Overproduction of KatA in $S$. meliloti bacteroids was detected at the mRNA and protein levels (Becker et al. 2004; Djordjevic et al. 2003).

Nitric oxide (NO) is a signaling and defense molecule involved in establishing an effective Rhizobium-legume symbiosis (Boscari et al. 2013). Recent studies showed that both plant and bacteria control NO concentration in $M$. truncatula nitrogen-fixing nodules. Nitrate-NO respiration processes could play a role in maintaining the energy status required for nitrogen fixation under oxygen-limiting conditions (Horchani et al. 2011). The bacterial NO detoxification response also plays a pivotal role in the prevention of early nodule senescence, and the maintenance of efficient symbiosis. Hmp flavohemoglobin is a major NO-detoxifying enzyme in S. meliloti (Meilhoc et al. 2010). A mutation in Hmp/SMa1191 in Rm2011 increased NO levels and led to rapid senescence of $S$. meliloti-M. truncatula nodules (Cam et al. 2012), indicating its importance in NO detoxification in symbiosis. Flavohemoglobin Hmp/Smed_5247 was attributed to general-function proteins, suggesting its role in both freeliving and symbiotic lifestyles of $S$. medicae (Supplementary Table S5).

\section{Protein export.}

Molecular chaperones play crucial roles in partitioning newly synthesized cell polypeptides as cytosolic, integral membrane, or exported proteins. Chaperones such as DnaK and GroEL are strongly involved in protein translocation by posttranslational targeting of presecretory proteins to the Sec and Tat 
translocation systems facilitating cell signaling (Castanié-Cornet et al. 2014). Many proteins comprising the Sec translocation pathway (SecD1/Smed-1174, SecD2/Smed_0181, SecY/Smed_1006, and SecA/Smed_2518) were found in both free-living and symbiotic proteomes as general-function proteins. However, SecB/ Smed_3214 was highly induced during symbiosis (Supplementary Fig. S1.11), indicating the involvement of bacterial protein secretion in establishing or maintaining an effective nitrogen-fixing symbiosis.

\section{Nitrogen and amino acid transport and metabolism.}

The current model of global changes in bacteroid metabolism implies that the induction of $\mathrm{N}_{2}$ fixation is coupled with decreased assimilation of ammonia into amino acids (Patriarca et al. 2002). Transcriptomic and proteomic analysis of S. meliloti symbiosis showed downregulation of glutamine synthetases GSI and GSII in the nodules (Becker et al. 2004; Djordjevic et al. 2003; Galibert et al. 2001). In agreement with this model, a number of proteins involved in ammonia assimilation such as GSI and GSII, aspartate aminotransferases AatA/Smed_2233 and Smed_0167, glutamate-ammonia-ligase adenylyltransferase GlnE/Smed_0640, and GltB/Smed_2711 (GOGAT) were identified as free-living-specific proteins.

As in other bacteria, Sinorhizobium catabolism of nitrogencontaining compounds is mainly controlled by a signal cascade that uses protein modification to transcriptionally and posttranslationally regulate nitrogen assimilation enzymes (Udvardi and Poole 2013). This cascade comprises the bifunctional uridylyltransferase/uridylyl-cleavage enzyme GlnD, two PII proteins (GlnB and GlnK0, and the two-component regulatory system $\mathrm{NtrB}$ and NtrC. In S. meliloti, PII proteins are not essential for triggering the induction of symbiotic nitrogen fixation (Yurgel et al. 2010). On the other hand, a truncated GlnD sensor protein substantially influences the regulation of nitrogen exchange in symbiosis (Yurgel and Kahn 2008; Yurgel et al. 2012). According to the model, GlnD/Smed_0031 was found in the general-function protein group, while GlnK/Smed_3050, NtrC/Smed_1090, and NtrB/Smed_1089 were part of free-living-specific proteins. GlnB was overrepresented in nodules, suggesting that, although GlnB may not be not essential for symbiosis (Yurgel et al. 2010), it is likely to be involved in bacteroid metabolism (Supplementary Fig. S1.12).

Surprisingly, no significant differences were detected between free-living-specific, nodule-specific, and general-function proteins in the representation of functional category "amino acid transport and metabolism" (Fig. 3). The transport of plantderived Bra is required to alleviate symbiotic auxotrophy in $R$. leguminosarum and the uptake of Bra is critical for establishing an $\mathrm{N}_{2}$-fixing symbiosis between $R$. leguminosarum and pea (Hosie et al. 2002; Lodwig et al. 2003). The presence of the transporter proteins in both free-living-cells and nodules suggests that transport of Bra could also be active in $S$. medicae during both lifestyles (Supplementary Fig. S1.13). In R. leguminosarum, it was shown that the Bra transporter can use two solute binding proteins: BraC, which has a wide range amino acid specificity, and BraC3, with a specificity restricted to Bra (Hosie et al. 2002). Three annotated homologs of the solute binding Bra transport proteins were identified in $S$. medicae in our analysis. LivK/Smed_2392 and LivJ/Smed_0538 protein was similarly represented in both free-living and symbiotic proteomes while the other protein, Smed_5345, was found only in freeliving cells. Additionally, proteins comprising probable highaffinity Bra transport ABC transporter LivF/Smed_2394 and LivG/Smed_2395 and general amino acid transport (Aap) were in the general-function protein group.

In contrast to the $R$. leguminosarum-pea symbiosis, in which rhizobia rely on the plant-derived Bra for nitrogen fixation
(Hosie et al. 2002; Lodwig et al. 2003; Prell et al. 2010), the analysis of Bra auxotrophs in S. meliloti showed that isoleucine and valine are limiting in alfalfa nodules and the bacteria synthesize these compounds while establishing nitrogen fixation (de las Nieves Peltzer et al. 2008). All of the bacterial enzymes needed to make Bra were found in both free-living and symbiotic proteomes (Supplementary Fig. S1.14). The pathway used for Bra degradation was underrepresented in the symbiotic proteome (Supplementary Fig. S1.15), suggesting differences in the role of Bra between $R$. leguminosarum-pea and $S$. medicae-M. truncatula symbiosis. Similarly, histidine biosynthetic enzymes are present in symbiosis whereas proteins degrading histidine to glutamate were repressed (Supplementary Fig. S1.16)

\section{Dicarboxylate transport, TCA cycle, pyruvate, and carbon storage compound metabolism.}

Dicarboxylic acids such as malic acid are the major carbon source for nitrogen-fixing bacteroids (Yurgel and Kahn 2004). The enzymes composing the $S$. meliloti Rm1021 TCA cycle are needed for nitrogen fixation (Terpolilli et al. 2012), as is the DctA dicarboxylate transport protein (McDermott and Kahn 1992; Yurgel and Kahn 2005). Despite the fact that the S. medicae free-living cells for proteome analysis were grown on malate as the sole carbon source, the DctA/Smed_4178 dicarboxylate transport protein was found only in the symbiotic proteome. Several DctP TRAP dicarboxylate transporter subunits (Smed_3743, Smed_3817, Smed_3688, Smed_4748, Smed_3840, Smed_2480, Smed_3836, Smed_5701, Smed_1719, Smed_1941, Smed_5134, Smed 4968, and Smed1442) were found in free-living-specific and general-function protein groups. The DctP TRAP system is not sufficient for growth on malate in free-living S. meliloti cells (Yurgel and Kahn 2004) but its efficiency in malate transport in free-living $S$. medicae cells has not been evaluated. However, it is possible that, because DctA/Smed_4178 abundance was relatively low in the nodule proteome, it could be present in free-living cells in amounts below our detection limit.

Most of the $S$. medicae TCA cycle enzymes were present at higher concentration in symbiosis (Supplementary Fig. S1.17), whereas we could not detect any alteration in pyruvate metabolic enzymes between free-living cells and in symbiosis (Supplementary Fig. S1.18). Several enzymes of the $S$. meliloti and B. japonicum TCA cycle had previously been identified in bacteroids (Delmotte et al. 2010; Djordjevic et al. 2003; Natera et al. 2000). An increase in $S$. medicae TCA enzymes from infection to nitrogen-fixing zone in nodules was also reported previously (Ogden et al. 2017). S. meliloti has two malic enzymes, Tme and Dme, which convert malate to pyruvate. Pyruvate can be decarboxylated by pyruvate dehydrogenase $(\mathrm{PdhA} / \mathrm{PdhB})$ to generate acetyl-CoA. The $\mathrm{NAD}^{+}$-dependent malic enzyme (Dme) is essential (Zhang et al. 2012) for S. meliloti nitrogen fixation (Driscoll and Finan 1996). Both malic enzymes were detected in our study, with Dme/Smed_1558 as a general-function protein and Tme/Smed_0029 as a part of the free-living-specific protein group. In contrast to a transcriptional study of $S$ meliloti bacteroids (Becker et al. 2004), pyruvate dehydrogenase Pdh/ Smed_1076-Smed_1078 was overrepresented in the nodule proteome. In Sinorhizobium NGR234, a lack of Dme can be partially compensated by phosphoenolpyruvate carboxykinase PckA/Smed_3253; however, this enzyme is decreased in abundance in nodules and we would predict that a dme mutant of $S$. medicae would not be able to fix nitrogen. Additionally, aconitase AcnA/Smed_3083 and citrate synthase GltA/Smed_1144 increased in abundance during symbiosis (Supplementary Fig. $\mathrm{S} 1.17)$, suggesting more emphasis on the TCA cycle in bacteroids compared with malate-grown free-living cells.

$S$. meliloti produces poly- $\beta$-hydroxybutyrate (PHB) and glycogen during free-living growth (Aneja and Charles 1999; 
Hirsch et al. 1983) and strains unable to synthesize these compounds were able to form nodules and fix nitrogen (Hirsch et al. 1983). In $S$. medicae, 1,4- $\alpha$-glucan branching enzyme GlgB/ Smed_2740, glycogen debranching enzyme GlgX/Smed_4409, $\beta$-ketothiolase PhaA/Smed_3117, and putative intracellular PHB depolymerase Smed_3233 were in the free-living-specific group, suggesting that biosynthesis of PHB and glycogen carbon storage polymers is decreased in the $S$. medicae symbiosis. S. meliloti Rm1021 enzymes composing the PHB biosynthetic pathway were also decreased in abundance in symbiosis (Natera et al. 2000). These data suggest that synthesis of carbon storage compounds in the form of $\mathrm{PHB}$ and glycogen is important to $S$. medicae free-living cells but not in planta. Moreover, enzymes of the Calvin-Benson-Bassham (CBB) cycle gene cluster, which includes fructose-1,6-bisphosphate aldolase CbbA/Smed_3923, phosphoribulokinase CbbP/Smed_3921, and HTH-type transcriptional regulator CbbR/Smed_3919, were in the free-living-specific protein group, suggesting an active $\mathrm{CBB}$ cycle in free-living cells but not in bacteroids. These finding are in contrast with a previous report on the importance of bacterial $\mathrm{RuBisCO}$ in the establishment of Bradyrhizobium/Aeschynomene symbiosis (Gourion et al. 2011). On the other hand, S. meliloti Rm1021 depends on the $c b b$ operon for formate-dependent auxotrophic growth (Pickering and Oresnik 2008).

\section{Carbohydrate transport and metabolism.}

Few significant differences were detected between free-livingspecific, nodule-specific, and general-function proteins in the functional category "Carbohydrate transport and metabolism" despite the differences in potential substrates for transport. No single sugar catabolism mutation has been shown to block nitrogen fixation and sugars are not actively transported into bacteroids (Udvardi and Poole 2013), nor do mutations in sugar uptake affect nitrogen fixation in $R$. leguminosarum (Ronson and Primrose 1979) or S. meliloti (Lin et al. 2009; Poysti et al. 2007; Willis and Walker 1999). In our proteome analysis, putative fructose ABC-type transport system FrcA/Smed_0104, putative C6 polyol ABC transporter SmoE/Smed_2358 and SmoK/ Smed_2355, and $\alpha$-glucoside ABC transporter AglG/Smed_0294 proteins were found to be part of the nodule-specific proteome. However, a number of sugar transporters were more abundant in free-living cells (Supplementary Fig. S1.13), despite the lack of substrates.

\section{Glycolysis and gluconeogenesis.}

With the exception of aldose 1-epimerase GalM/Smed_3031, we were able to detect all enzymes making up the glycolytic or gluconeogenic pathways in the nodule proteome, and most of the proteins in this pathway were equally represented in freeliving and symbiotic proteomes (Supplementary Fig. S1.19). However, fructose-bisphosphate aldolase, FbaB/Smed_2654, and phosphoenolpyruvate carboxykinase PckA/Smed_3253, which catalyze the committed steps of gluconeogenesis, were highly induced in free-living cells, probably because malate was the sole carbon source. In S. meliloti and Bradyrhizobium japonicum, several enzymes or transcripts of the pathway proteins were also identified in free-living cells and in bacteroids (Becker et al. 2004; Delmotte et al. 2010; Djordjevic et al. 2003; Natera et al. 2000). Gluconeogenesis is required when growing on malate, and the lower level of PckA in bacteroids suggests that some hexoses are obtained from the plants, though at lower levels that would be needed for their use as carbon or energy sources. In $S$. meliloti, mutations in 3-phosphoglycerate kinase, enolase, and glyceraldehyde-3-phosphate dehydrogenase caused a Fix $^{-}$phenotype, which was attributed to impaired gluconeogenesis in the mutants, although mutating the committed step of gluconeogenesis, PckA, did not affect the symbiotic performance of Rm1021 (Finan et al. 1991). The number of sugar transporters in the nodule bacterial proteome suggests that these may be involved in importing these compounds or their precursors.

\section{Pentose phosphate pathway.}

Like the glycolytic and gluconeogenic pathways, most of the enzymes making up the pentose phosphate pathway were equally represented in free-living and symbiotic proteomes. (Supplementary Fig. S1.20). The only exception was a symbiotically overproduced putative transaldolase Smed_2928, an enzyme that balances metabolites in the pentose-phosphate pathway.

\section{ABC transporters.}

Molybdate, phosphate, manganese, and iron uptake are important in symbiosis but, in many cases, the actual effect of metal and ion limitation depends on the plant-bacteria combination (Udvardi and Poole 2013). We detected the high-affinity phosphate transporter (PstB) only in the free-living proteome; the putative pit accessory protein Smed_3394 was in both (Supplementary Fig. S1.13). This is in agreement with previously published data that the low-affinity Pit1 transporter is the main system used in bacteroids (Yuan et al. 2006). $\mathrm{Mn}(\mathrm{II}) / \mathrm{Fe}(\mathrm{II})$ transporter SitA/Smed_2914/SitB/Smed_2915 and putative molybdate-binding periplasmic $\mathrm{ABC}^{-}$transporter ModA/ Smed_2821 proteins were found in both proteomes. The S. meliloti iron- and manganese-dependent transcriptional regulator Fur/Smed_2913 is required for Mn(II)-dependent repression of the sitABCD operon (Chao et al. 2004). In our study, Smed_2913 was present only in the free-living proteome, consistent with a previous report showing that Fur is not required for a successful symbiosis (Chao et al. 2004; Roberts 2007).

The plant must provide the bacteroids with sufficient iron to support nitrogen fixation because iron is an essential component of several proteins - a functional nitrogenase enzyme requires 47 iron atoms (Hausinger 2019). Characterization of iron transport in legume nodules reveals systems supporting iron translocation across both the symbiosome and bacteroid membranes. Our proteome analysis revealed that an $\mathrm{Fe}^{+3}$ transporter, FbpA/ Smed_0327; a putative iron uptake ABC transporter periplasmic solute-binding protein, Smed_4418; and hemin-binding proteins, HmuT/Smed_2339, were more abundant in the nodules, implying that the corresponding transport systems were involved in importing iron-containing compounds in the symbiosis. In $S$. meliloti, a number of iron transporter proteins were also detected in bacteroids (Djordjevic et al. 2003).

Several solute-binding transport proteins predicted to bind glycine-betaine/proline (PrbA/Smed_2178 and Smed_1768), or other osmoprotectants (OpuA/Smed_2307), were found in the general-function protein group. In $S$. meliloti, rapid acquisition of betaines in response to osmotic upshock is critical for survival (Boscari et al. 2002), and the Prb ABC transporter is critical for osmoprotection by betaines (Alloing et al. 2006). These putative betaine transport systems were also detected in S. meliloti bacteroids (Djordjevic et al. 2003). However, we did not detect the BetT choline/glycine-betaine transporter, which is induced by high osmolarity (Alloing et al. 2006), suggesting that the bacteria were not osmotically stressed in free-living or symbiotic conditions. The betCBA operon proteins were found in the nodule-specific protein group, in agreement with previous reports (Mandon et al. 2003).

\section{Cell wall, membrane, or envelope biogenesis.}

Exopolysaccharide (EPS) biosynthesis and export and lipopolysaccharide (LPS) production were repressed in symbiosis. A number of proteins that were previously shown to be involved in EPS or LPS formation in S. meliloti or B. japonicum such as 
Wga, Wgc, Wge, Wgc, Wgg, Exo, and MurC (Becker et al. 1997; Chang et al. 2008) were specific to free-living proteins. The high-molecular-weight EPSI protects $S$. meliloti against the antimicrobial activities of host NCR peptides in late-stage symbiosis (Arnold et al. 2018). These findings, combined with the low level of BacA detection in the symbiotic proteome, might indicate fundamental differences between $S$. meliloti and $S$. medicae in their mechanisms that modulate the exposure of the internalized rhizobia to the NCR peptides.

The outer-membrane proteins TolC/Smed_1149, which affects S. meliloti stress response and symbiotic performance (Cosme et al. 2008), and Omn/Smed_1138, which is essential for virulence of invasive members of the Rhizobiaceae family (Guzman-Verri et al. 2002), were general-function proteins.

\section{Plant-induced proteins.}

We also looked at proteins that were shown to be induced by plant flavonoids (Barnett et al. 2004; Capela et al. 2005) or in early stages of invasion (Roux et al. 2014). Only two proteins, Smed_2795/SMc03168 and GroEL heat shock protein Smed_1281/SMb21566, were found in the nodule-specific proteome, suggesting either a small role for plant flavonoids on general bacterial development in nodules or that this involvement is substantial in only a small fraction of the nodule tissue.

\section{Some WSM419 proteins are not present in S. meliloti Rm1021.}

Identifying close homologs of $S$. meliloti Rm1021 genes in the $S$. medicae WSM419 genome helped us to assign possible functions to $S$. medicae proteins, and it also allowed us to identify 128 proteins that were present in the WSM419 proteomes but did not have close homologs in $S$. meliloti (Supplementary Table S9). Some of these proteins might be related to the better symbiotic performance of WSM419 in M. truncatula. A comparative genomic analysis of core and accessory genomes in Sinorhizobium strains composing five genospecies showed some alterations between strains in the strategy used to obtain maximum compatibility with a host plant (Sugawara et al. 2013).

Approximately $6 \%$ of the nodule-specific $S$. medicae proteins have no $S$. meliloti homolog and may play a role in formation of a more effective nitrogen-fixing symbiosis between $S$. medicae and $M$. truncatula. The gene cluster Smed_6101-Smed_6103, Smed_6105-Smed_6109, and Smed_6111 and the two proteins Smed_1901 and Smed_1902 were highly induced in symbiosis. Eight of these proteins do not have probable assigned functions and seven of them do not have close homologs in S. meliloti.

An abundant predicted glucosidase, Smed_5985, could be involved in producing low molecular weight (LMW)-EPS by depolymerization of high molecular weight EPS. Proteins highly similar to Smed_5985 are in S. meliloti BL225C (Lucas et al. 2012a), R. leguminosarum bv. trifolii WSM2012 (Lucas et al. 2012b), and several $R$. etli strains (Fauvart et al. 2011; González et al. 2006; Skorupska et al. 2006). EPS is important in rhizobia infection and nodule formation, as well as in bacteroid maturation and suppression of plant defense (Skorupska et al. 2006). In work to be published separately, we have shown that transferring Smed_5985 into S. meliloti Rm1021 increases its effectiveness with $M$. truncatula (Ghosh et al. 2021). In S. meliloti Rm1021, the endo-1,3-1,4- $\beta$-glycanases ExoK and ExsH contribute to production of symbiotically active LMW-EPS I (Becker et al. 1993). As a novel glucosidase, Smed_5985 might affect EPS composition in WSM419 and influence infection and nodule formation in association with $M$. truncatula A17.

Another protein that might be related to the better symbiotic performance of WSM419 in M. truncatula is aminocyclopropanecarboxylate (ACC) deaminase Smed_6456, which was found at roughly the same level in both WSM419 proteomes. ACC deaminase degrades ACC, the immediate precursor of ethylenea plant growth hormone that controls plant development, stimulates defense responses that interfere with nodulation, and inhibits early symbiotic responses such as calcium spiking (Gresshoff et al. 2009; Ma et al. 2003, 2004; Oldroyd et al. 2001). M. truncatula is more sensitive to ethylene than $M$. sativa (alfalfa), the common host for $S$. meliloti (Smith and Long 1998), and the presence of an ACC deaminase might lower ethylene and improve nodulation and nodule function. In separate work, we have shown that transferring Smed_6456 to $S$. meliloti $\mathrm{Rm} 1021$ increases $M$. truncatula seedling biomass in symbiosis (Ghosh et al. 2021).

A third protein of interest is Smed_3503, a predicted component of an extradiol dioxygenase, which also increases the biomass of the Rm1021 symbiosis with $M$. truncatula compared with Sm1021 (Ghosh et al. 2021). Smed_3503 is found in all 31 of the $S$. medicae genome sequences currently available in the Joint Genome Initiative databases (Chen et al. 2021) but is found in less than $10 \%$ of the other Sinorhizobium isolates.

\section{The proteome and nodule development.}

The work presented here examined whole nodules produced in the Sinorhizobium-Medicago symbiosis, which incorporates both symbiotic differentiated and nodule-internalized free-living rhizobia. These are indeterminate nodules, which are characterized by a developmental gradient of plant and bacterial cells, and further work from our laboratory has examined the abundance of proteins and metabolites in various parts of this developmental gradient (Ogden et. al. 2017). The proteomes generated in that article are not as complete as those presented here but, because the proteomes in Ogden et al. (2017) were collected from subnodule fractions, they provide information about the developmental changes that are associated with symbiotic specialization.

\section{Conclusions.}

We used MS/MS to gain substantially more detailed information about the bacterial proteome present in the symbiotic association between $M$. truncatula A17 and $S$. medicae strain WSM419 than was available previously. The availability of the genome sequence of WSM419 makes this strain an attractive model to study the Sinorhizobium-Medicago association compared with $S$. meliloti Rm1021/Rm2011, which forms a less successful symbiosis with the model plant $M$. truncatula A17. We compared the global bacterial proteomes obtained from wholeplant nodules and free-living cells. While obtaining the bacterial free-living and symbiotic proteomes, we also obtained plant nodule proteomes, which were included without analysis. This approach gives us the possibility to understand the global metabolic changes that occur in a single plant-bacteria system and lead to establishment of an effective nitrogen-fixing symbiosis. The underlying data set provides the basis for further work by identifying accurate mass tags of proteins likely to be present, thus enabling more detailed analysis of development in the system.

In total, 3,215 distinct proteins were identified in free-living and symbiotic proteomes of $S$. medicae, approximately half of all predicted proteins. Of these proteins, 1,361 displayed a strong lifestyle specialization, 1,131 proteins were similarly represented in both proteomes, and 723 were found either in one or both of the proteomes but often at a low enough abundance that they could not be clearly assigned to any of these classes. Our data indicate an activation of bacterial stress responses in the $S$. medicae-M. truncatula symbiosis. We identified a number of lifestyle-specific proteins that are not present in S. meliloti Rm1021. Understanding the roles of these proteins in the interaction 
between WSM419 and M. truncatula might clarify factors affecting the lower effectiveness of S. meliloti Rm1021 in the MtA17 symbiosis. Evaluation of the role of some of these proteins in $S$. meliloti-M. truncatula symbiosis is underway.

\section{MATERIALS AND METHODS}

\section{Materials.}

Urea, dithiothreitol (DTT), ammonia bicarbonate, $\mathrm{CaCl}_{2}$, trifluoroacetic acid (TFA), polyvinylpolypyrrolidone (PVPP), and a protease inhibitor cocktail for plant cell and tissue extracts (P9599) were from Sigma (Milwaukee, WI, U.S.A.). Coomassie and BCA protein assay reagents were from Thermo Scientific (Rockford, IL, U.S.A.).

\section{Preparation of nodules and roots from the plants inoculated with $S$. medicae WSM419.}

The plant growth boxes were prepared as follows: Turface (Profile Products, Buffalo Grove, IL, U.S.A.) was rinsed until water was clear, then autoclaved. Wet, sterile Turface was placed into sterile Magenta boxes (Sigma GA-7) with holes in the bottom covered by a sterile square of filter paper. The boxes were held in glass casserole dishes, which had been disinfected with $70 \%$ EtOH. Two surface-sterilized M. truncatula A17 seeds were placed in each box just beneath the surface and $1 \mathrm{~cm}$ of nitrogen-free plant nutrient solution (Supplementary Table S10) (McDermott and Kahn 1992; Yurgel and Kahn 2005) was added to the casserole dish. The boxes were covered with a sheet of Saran Wrap to raise humidity and placed in the growth chamber. After seed germination, the Saran Wrap was removed and only one seedling was left in each box. The plants were inoculated with $1 \mathrm{ml}$ of sterile nitrogen-free plant nutrient solution containing $10^{7}$ cells of $S$. medicae strain WSM419 (Reeve et al. 2010) and grown in a growth chamber at $21^{\circ} \mathrm{C}$ with a cycle of $16 \mathrm{~h}$ of light and $8 \mathrm{~h}$ of darkness. Sterile nitrogen-free plant nutrient solution was added to the casserole dishes to maintain moisture in the boxes. M. truncatula nodules were harvested 21 days postinoculation and immediately frozen in liquid nitrogen.

\section{Free-living cell preparation.}

S. medicae strain WSM419 was first grown in minimal media (Somerville and Kahn 1983) supplemented with 0.2\% sodium malate as carbon source and $0.02 \%$ sodium glutamine as nitrogen source (Min-Malate-Gln) at $30^{\circ} \mathrm{C}$ with agitation for $48 \mathrm{~h}$. Then, $20 \mathrm{ml}$ of the culture was added to 1 liter of fresh MinMalate-Gln and the cells were grown with agitation in the plant growth chamber at $21^{\circ} \mathrm{C}$. When the culture density reached an optical density at $600 \mathrm{~nm}$ of approximately 1.000, after 5 days postinoculation (stationary phase), the cells were harvested by centrifugation and immediately frozen in liquid nitrogen.

\section{Extraction of nodule proteins.}

Nodules with three biological replicates were placed into a clean mortar and pestle which had been prefrozen at $-80^{\circ} \mathrm{C}$ overnight, followed by the addition of hydrated PVPP $(100 \mathrm{mg} / \mathrm{g}$ of plant tissue). Samples were completely frozen with liquid nitrogen and ground for 2 to 3 min until the liquid nitrogen had evaporated. Once ground, $300 \mu \mathrm{l}$ of water containing a plant proteinase inhibitor cocktail at the concentration recommended by the manufacturer was added to the cold mortar and frozen immediately. The samples were ground until they were thawed. The liquid samples were further lysed by bead beating with $0.1 \mathrm{~mm}$ Zirconia/Silica Beads in a Bullet Blender (Next Advance, Troy, NY, U.S.A.) set at speed 8 for $3 \mathrm{~min}$ at $4^{\circ} \mathrm{C}$. After bead beating, samples were centrifuged at $4^{\circ} \mathrm{C}$ for 10 min at 5,000 relative centrifugal force (rcf) to remove PVPP and debris. A small portion of the supernatant was used for Coomassie assay (Bradford 1976) to measure protein concentration. The rest of the supernatant was mixed with prechilled $\left(-20^{\circ} \mathrm{C}\right)$ chloroform/methanol $(2: 1$, volume ratio) in a $5: 1$ ratio over sample volume, placed in ice for $5 \mathrm{~min}$, vortexed briefly, and centrifuged at $15,000 \mathrm{rcf}$ for $10 \mathrm{~min}$ at $4^{\circ} \mathrm{C}$. The protein interlayer containing the proteins from the plant and bacteroids was dried for subsequent tryptic digestion, followed by liquid chromatography mass spectrometry (LC-MS) analysis.

\section{Extraction of proteins}

\section{from the free-living $S$. medicae WSM419.}

Frozen bacterial cells were suspended in $\mathrm{NH}_{4} \mathrm{HCO}_{3}$ buffer ( $\mathrm{pH} \mathrm{8,100} \mathrm{mM)} \mathrm{and} \mathrm{lysed} \mathrm{by} \mathrm{bead} \mathrm{beating} \mathrm{(Cao} \mathrm{et} \mathrm{al.} \mathrm{2012)}$ with $0.1 \mathrm{~mm}$ Zirconia/Silica Beads (Biospec Products) in a Bullet Blender set at speed 8 for $3 \mathrm{~min}$ at $4^{\circ} \mathrm{C}$, followed by centrifugation to remove cell debris. The resulting supernatant was harvested. The beads were washed once with $200 \mu \mathrm{l}$ of $\mathrm{NH}_{4} \mathrm{HCO}_{3}$ buffer $(\mathrm{pH} 8,100 \mathrm{mM})$, followed by centrifugation (Eppendorf Centrifuge 5418; Hauppauge, NY, U.S.A.) at maximum speed for $5 \mathrm{~min}$. The supernatant was then transferred to the previous supernatant fraction.

\section{Tryptic digestion.}

The resulting proteins were denatured and reduced by adding urea $(8 \mathrm{M})$ and DTT $(5 \mathrm{mM})$ with incubation at $60^{\circ} \mathrm{C}$ for 30 min with gentle shaking. Samples were diluted by adding nine volumes of ammonia bicarbonate buffer $(50 \mathrm{mM}$, pH 7.8), then digested for $3 \mathrm{~h}$ at $37^{\circ} \mathrm{C}$ with sequencing-grade trypsin (1:50, $\mathrm{wt} / \mathrm{wt}$ ) (Promega Corp.) in the presence of $\mathrm{CaCl}_{2}(1 \mathrm{mM})$. The tryptic digest was acidified with diluted TFA (final $\mathrm{pH} 3$ to 4), followed by passage through C-18 SPE columns (Supelco, St. Louis) for peptide cleanup according to the manufacturer protocols.

\section{LC-MS analysis.}

To decrease the complexity of the samples introduced into the mass spectrometer, allowing deeper analysis, high-pH reversephase chromatography (Wang et al. 2011) was used to fractionate the peptides $(100 \mu \mathrm{g})$ from the nodule or free-living $S$. medicae WSM419 into 12 fractions. The tryptic peptides from each fraction were separated by reversed-phase C18 high-performance liquid chromatography (Nicora et al. 2013). The separated peptides were detected by a Thermo Fisher Scientific LTQ Orbitrap Velos mass spectrometer (Thermo Fisher Scientific, San Jose, CA, U.S.A.) coupled with an electrospray ionization interface using custom-designed etched tips (Kelly et al. 2006).

\section{Data analysis.}

The generated MS/MS spectra were searched using MS-GF+ (Kim and Pevzner 2012) against a protein database that combined the target sequences of 6,415 S. medicae WSM419 proteins (5 February 2008) obtained from UniProt and reversed sequences. The database also contained 47,529 predicted proteins of M. truncatula (25 August 2010; downloaded from J. Craig Venter Institute) because plant tissue was also in the samples we analyzed. Common contaminants were included in the data analysis pipeline filter. The identified peptides were filtered by adjusting the MS-GF+ (Kim et al. 2008) cutoff value to make the false discovery rate less than $1 \%$. Protein assignment required at least two unique peptide matches and, thus, all proteins we considered valid have a spectral count of at least 2 . Only 17 peptides belonging to eight proteins were found in this data set that had an ambiguous assignment because of the presence of the peptide in both plant and bacterial databases. "Count of peptides" is the number of unique peptides observed for a 
corresponding protein and "Spectral count" refers to the number of unique peptide-spectrum matches observed for a given protein. The spectral count data are a semiquantitative measurement of relative protein abundance, and was normalized followed by statistical analysis using the inverted $\beta$-binomial model (Pham and Jimenez 2012). Protein levels were considered as significantly changed when adjusted $P$ values were less than 0.01 and when there was an equal to or greater than twofold change in the normalized spectra counts for the protein observed in the different growth conditions, or the normalized spectral count averaged from three biological replicates was greater than three for the protein observed in only one growth condition. All statistical analyses were performed in R ( $\mathrm{R}$ Core Team 2008).

The pathway analysis of identified proteins was performed by using the pathway mapping tools in KEGG. COG functional classification was done based on WSM419 genome annotation (Reeve et al. 2010).

\section{Genetic techniques.}

DNA manipulations were carried out following standard procedures (Sambrook et al. 1989). The deletion mutants were constructed using an insertion and excision strategy (Yurgel and Kahn 2005), with some modifications. To construct the $S$. meliloti nerA deletion mutant, PCR was used to amplify the two chromosomal regions $(0.5$ and $0.6 \mathrm{~kb})$ flanking the regions to be deleted using primers listed in Supplementary Table S11. To construct the $S$. medicae nerA deletion mutant, chromosomal regions $(0.5$ and $0.6 \mathrm{~kb})$ flanking the regions to be deleted were synthesized using Genscript services. The deletions were confirmed by PCR using primers located outside of the regions flanking those used to construct the deletions, as well as primers located in the deleted regions (Supplementary Table S11).

Zone-of-inhibition assays were performed to measure the sensitivities of strains to hydrogen peroxide. The strains tested were grown for 2 days in yeast mannitol broth (YMB) prior to the assay. To make the lawns of bacteria for the assay, $100 \mu \mathrm{l}$ of cells was added to $3.5 \mathrm{ml}$ of YMB top agar ( $0.7 \%$ agar, cooled to $55^{\circ} \mathrm{C}$ ), mixed, then poured on top of a YMB plate. Ten plates were made for each strain. Whatman number 1 filter paper disks, $6 \mathrm{~mm}$ in diameter, were prepared by using a hole punch, and sterilized. A $0.5-\mathrm{mg} / \mathrm{ml}$ solution of hydrogen peroxide was prepared and applied to the disks to obtain the following final hydrogen peroxide concentrations: $30,6,1.2,0.24$, and $0.048 \%$. The disks were aseptically placed on the centers of the pour plates. The plates were then incubated at $30^{\circ} \mathrm{C}$ for 3 days, and the zones of inhibition were measured.

\section{LITERATURE CITED}

Alloing, G., Travers, I., Sagot, B., Le Rudulier, D., and Dupont, L. 2006. Proline betaine uptake in Sinorhizobium meliloti: Characterization of Prb, an opp-like ABC transporter regulated by both proline betaine and salinity stress. J. Bacteriol. 188:6308-6317.

Aneja, P., and Charles, T. C. 1999. Poly-3-hydroxybutyrate degradation in Rhizobium (Sinorhizobium) meliloti: Isolation and characterization of a gene encoding 3-hydroxybutyrate dehydrogenase. J. Bacteriol. $181: 849-857$

Arnold, M. F. F., Penterman, J., Shabab, M., Chen, E. J., and Walker, G. C. 2018. Important late-stage symbiotic role of the Sinorhizobium meliloti exopolysaccharide succinoglycan. J. Bacteriol. 200:e00665-17.

Barnett, M. J., Toman, C. J., Fisher, R. F., and Long, S. R. 2004. A dualgenome symbiosis chip for coordinate study of signal exchange and development in a prokaryote-host interaction. Proc. Natl. Acad. Sci. U.S.A. 101:16636-16641.

Bastiat, B., Sauviac, L., and Bruand, C. 2010. Dual control of Sinorhizobium meliloti RpoE2 sigma factor activity by two PhyR-type two-component response regulators. J. Bacteriol. 192:2255-2265.

Becker, A., Bergès, H., Krol, E., Bruand, C., Rüberg, S., Capela, D., Lauber, E., Meilhoc, E., Ampe, F., de Bruijn, F. J., Fourment, J.,
Francez-Charlot, A., Kahn, D., Küster, H., Liebe, C., Pühler, A., Weidner, S., and Batut, J. 2004. Global changes in gene expression in Sinorhizobium meliloti 1021 under microoxic and symbiotic conditions. Mol. Plant-Microbe Interact. 17:292-303.

Becker, A., Kleickmann, A., Arnold, W., and Pühler, A. 1993. Analysis of the Rhizobium meliloti exoH/exoK/exoL fragment: ExoK shows homology to excreted endo-beta-1,3-1,4-glucanases and ExoH resembles membrane proteins. Mol. Gen. Genet. 238:145-154.

Becker, A., Rüberg, S., Küster, H., Roxlau, A. A., Keller, M., Ivashina, T., Cheng, H. P., Walker, G. C., and Pühler, A. 1997. The 32-kilobase exp gene cluster of Rhizobium meliloti directing the biosynthesis of galactoglucan: Genetic organization and properties of the encoded gene products. J. Bacteriol. 179:1375-1384.

Bittner, A. N., Foltz, A., and Oke, V. 2007. Only one of five groEL genes is required for viability and successful symbiosis in Sinorhizobium meliloti. J. Bacteriol. 189:1884-1889.

Boscari, A., Del Giudice, J., Ferrarini, A., Venturini, L., Zaffini, A. L., Delledonne, M., and Puppo, A. 2013. Expression dynamics of the Medicago truncatula transcriptome during the symbiotic interaction with Sinorhizobium meliloti: Which role for nitric oxide? Plant Physiol. 161:425-439.

Boscari, A., Mandon, K., Dupont, L., Poggi, M. C., and Le Rudulier, D. 2002. BetS is a major glycine betaine/proline betaine transporter required for early osmotic adjustment in Sinorhizobium meliloti. J. Bacteriol. 184:2654-2663.

Bradford, M. M. 1976. A rapid and sensitive method for the quantitation of microgram quantities of protein utilizing the principle of proteindye binding. Anal. Biochem. 72:248-254.

Buckel, W., and Thauer, R. K. 2018. Flavin-based electron bifurcation, ferredoxin, flavodoxin, and anaerobic respiration with protons (Ech) or $\mathrm{NAD}^{+}$(Rnf) as electron acceptors: A historical review. Front. Microbiol. 9:401.

Cam, Y., Pierre, O., Boncompagni, E., Hérouart, D., Meilhoc, E., and Bruand, C. 2012. Nitric oxide (NO): A key player in the senescence of Medicago truncatula root nodules. New Phytol. 196:548-560.

Cao, L., Bryant, D. A., Schepmoes, A. A., Vogl, K., Smith, R. D., Lipton, M. S., and Callister, S. J. 2012. Comparison of Chloroflexus aurantiacus strain J-10-fl proteomes of cells grown chemoheterotrophically and photoheterotrophically. Photosynth. Res. 110:153-168.

Capela, D., Carrere, S., and Batut, J. 2005. Transcriptome-based identification of the Sinorhizobium meliloti NodD1 regulon. Appl. Environ. Microbiol. 71:4910-4913.

Capela, D., Filipe, C., Bobik, C., Batut, J., and Bruand, C. 2006. Sinorhizobium meliloti differentiation during symbiosis with alfalfa: A transcriptomic dissection. Mol. Plant-Microbe Interact. 19:363-372.

Castanié-Cornet, M. P., Bruel, N., and Genevaux, P. 2014. Chaperone networking facilitates protein targeting to the bacterial cytoplasmic membrane. Biochim. Biophys. Acta 1843:1442-1456.

Chang, W. S., Park, K. M., Koh, S. C., and So, J. S. 2008. Characterization of the Bradyrhizobium japonicum galE gene: Its impact on lipopolysaccharide profile and nodulation of soybean. FEMS Microbiol. Lett. 280:242-249.

Chao, T. C., Becker, A., Buhrmester, J., Pühler, A., and Weidner, S. 2004. The Sinorhizobium meliloti fur gene regulates, with dependence on $\mathrm{Mn}(\mathrm{II})$, transcription of the $\operatorname{sit} A B C D$ operon, encoding a metal-type transporter. J. Bacteriol. 186:3609-3620.

Chen, I. A., Chu, K., Palaniappan, K., Ratner, A., Huang, J., Huntemann, M., Hajek, P., Ritter, S., Varghese, N., Seshadri, R., Roux, S., Woyke, T., Eloe-Fadrosh, E. A., Ivanova, N. N., and Kyrpides, N. C. 2021. The IMG/M data management and analysis system v.6.0: New tools and advanced capabilities. Nucleic Acids Res. 49:D751-D763.

Cosme, A. M., Becker, A., Santos, M. R., Sharypova, L. A., Santos, P. M., and Moreira, L. M. 2008. The outer membrane protein TolC from Sinorhizobium meliloti affects protein secretion, polysaccharide biosynthesis, antimicrobial resistance, and symbiosis. Mol. PlantMicrobe Interact. 21:947-957.

de las Nieves Peltzer, M., Roques, N., Poinsot, V., Aguilar, O. M., Batut, J., and Capela, D. 2008. Auxotrophy accounts for nodulation defect of most Sinorhizobium meliloti mutants in the branched-chain amino acid biosynthesis pathway. Mol. Plant-Microbe Interact. 21: 1232-1241.

Delmotte, N., Ahrens, C. H., Knief, C., Qeli, E., Koch, M., Fischer, H. M., Vorholt, J. A., Hennecke, H., and Pessi, G. 2010. An integrated proteomics and transcriptomics reference data set provides new insights into the Bradyrhizobium japonicum bacteroid metabolism in soybean root nodules. Proteomics 10:1391-1400.

Djordjevic, M. A. 2004. Sinorhizobium meliloti metabolism in the root nodule: A proteomic perspective. Proteomics 4:1859-1872. 
Djordjevic, M. A., Chen, H. C., Natera, S., Van Noorden, G., Menzel, C., Taylor, S., Renard, C., Geiger, O., Weiller, G. F., and Sinorhizobium DNA Sequencing Consortium. 2003. A global analysis of protein expression profiles in Sinorhizobium meliloti: Discovery of new genes for nodule occupancy and stress adaptation. Mol. Plant-Microbe Interact. 16:508-524.

Driscoll, B. T., and Finan, T. M. 1996. NADP+-dependent malic enzyme of Rhizobium meliloti. J. Bacteriol. 178:2224-2231.

Earl, C. D., Ronson, C. W., and Ausubel, F. M. 1987. Genetic and structural analysis of the Rhizobium meliloti fixA, fixB, fixC, and fixX genes. J. Bacteriol. 169:1127-1136.

Farkas, A., Maróti, G., Durgő, H., Györgypál, Z., Lima, R. M., Medzihradszky, K. F., Kereszt, A., Mergaert, P., and Kondorosi, É. 2014. Medicago truncatula symbiotic peptide NCR247 contributes to bacteroid differentiation through multiple mechanisms. Proc. Natl. Acad. Sci. U.S.A. 111:5183-5188.

Fauvart, M., Sánchez-Rodríguez, A., Beullens, S., Marchal, K., and Michiels, J. 2011. Genome sequence of Rhizobium etli CNPAF512, a nitrogen-fixing symbiont isolated from bean root nodules in Brazil. J. Bacteriol. 193:3158-3159.

Ferguson, G. P., Roop, R. M., 2nd, and Walker, G. C. 2002. Deficiency of a Sinorhizobium meliloti BacA mutant in alfalfa symbiosis correlates with alteration of the cell envelope. J. Bacteriol. 184:5625-5632.

Finan, P. M., McWhinnie, E., Driscoll, B. T., and Watson, R. J. 1991. Complex symbiotic phenotypes result from gluconeogenic mutations in Rhizobium meliloti. Mol. Plant-Microbe Interact. 4:386-392.

Fitzpatrick, T. B., Amrhein, N., and Macheroux, P. 2003. Characterization of YqjM, an old yellow enzyme homolog from Bacillus subtilis involved in the oxidative stress response. J. Biol. Chem. 278:19891-19897.

Flores-Tinoco, C. E., Tschan, F., Fuhrer, T., Margot, C., Sauer, U., Christen, M., and Christen, B. 2020. Co-catabolism of arginine and succinate drives symbiotic nitrogen fixation. Mol. Syst. Biol. 16:e9419.

Galibert, F., Finan, T. M., Long, S. R., Puhler, A., Abola, P., Ampe, F., Barloy-Hubler, F., Barnett, M. J., Becker, A., Boistard, P., Bothe, G., Boutry, M., Bowser, L., Buhrmester, J., Cadieu, E., Capela, D., Chain, P., Cowie, A., Davis, R. W., Dreano, S., Federspiel, N. A., Fisher, R. F., Gloux, S., Godrie, T., Goffeau, A., Golding, B., Gouzy, J., Gurjal, M., Hernandez-Lucas, I., Hong, A., Huizar, L., Hyman, R. W. Jones, T., Kahn, D., Kahn, M. L., Kalman, S., Keating, D. H., Kiss, E., Komp, C., Lelaure, V., Masuy, D., Palm, C., Peck, M. C., Pohl, T. M., Portetelle, D., Purnelle, B., Ramsperger, U., Surzycki, R., Thebault, P., Vandenbol, M., Vorholter, F. J., Weidner, S., Wells, D. H., Wong, K., Yeh, K. C., and Batut, J. 2001. The composite genome of the legume symbiont Sinorhizobium meliloti. Science 293:668-672.

Ghosh, P., Adolphsen, K. N., Yurgel, S. N., and Kahn, M. L. 2021. Sinorhizobium medicae WSM419 genes that improve symbiosis between Sinorhizobium meliloti Rm1021 and Medicago truncatula Jemalong A17 and in other symbiotic systems. Appl. Environ. Microbiol. 87:e03004-20.

Gokulakannan, G. G., and Niehaus, K. 2010. Characterization of the Medicago truncatula cell wall proteome in cell suspension culture upon elicitation and suppression of plant defense. J. Plant Physiol. 167:1533-1541.

Gomes, D. F., Batista, J. S., Schiavon, A. L., Andrade, D. S., and Hungria, M. 2012a. Proteomic profiling of Rhizobium tropici PRF 81: Identification of conserved and specific responses to heat stress. BMC Microbiol. 12:84

Gomes, D. F., Batista, J. S., Torres, A. R., de Souza Andrade, D., Galli-Terasawa, L. V., and Hungria, M. 2012b. Two-dimensional proteome reference map of Rhizobium tropici PRF 81 reveals several symbiotic determinants and strong resemblance with agrobacteria. Proteomics 12:859-863.

González, V., Santamaría, R. I., Bustos, P., Hernández-González, I., Medrano-Soto, A., Moreno-Hagelsieb, G., Janga, S. C., Ramírez, M. A., Jiménez-Jacinto, V., Collado-Vides, J., and Dávila, G. 2006. The partitioned Rhizobium etli genome: Genetic and metabolic redundancy in seven interacting replicons. Proc. Natl. Acad. Sci. U.S.A. 103:3834-3839

Gourion, B., Delmotte, N., Bonaldi, K., Nouwen, N., Vorholt, J. A., and Giraud, E. 2011. Bacterial RuBisCO is required for efficient Bradyrhizobium/Aeschynomene symbiosis. PLoS One 6:e21900.

Gourion, B., Sulser, S., Frunzke, J., Francez-Charlot, A., Stiefel, P., Pessi, G., Vorholt, J. A., and Fischer, H. M. 2009. The PhyR-sigma(EcfG) signalling cascade is involved in stress response and symbiotic efficiency in Bradyrhizobium japonicum. Mol. Microbiol. 73:291-305.

Gresshoff, P. M., Lohar, D., Chan, P. K., Biswas, B., Jiang, Q., Reid, D., Ferguson, B., and Stacey, G. 2009. Genetic analysis of ethylene regulation of legume nodulation. Plant Signal. Behav. 4:818-823.

Guzman-Verri, C., Manterola, L., Sola-Landa, A., Parra, A., Cloeckaert, A., Garin, J., Gorvel, J. P., Moriyon, I., Moreno, E., and Lopez-Goni, I.
2002. The two-component system BvrR/BvrS essential for Brucella abortus virulence regulates the expression of outer membrane proteins with counterparts in members of the Rhizobiaceae. Proc. Natl. Acad. Sci. U.S.A. 99:12375-12380

Haag, A. F., Arnold, M. F., Myka, K. K., Kerscher, B., Dall'angelo, S., Zanda, M., Mergaert, P., and Ferguson, G. P. 2012. Molecular insights into bacteroid development during Rhizobium-legume symbiosis. FEMS Microbiol. Rev. 37:364-383.

Haag, A. F., Baloban, M., Sani, M., Kerscher, B., Pierre, O., Farkas, A., Longhi, R., Boncompagni, E., Hérouart, D., Dall'angelo, S., Kondorosi, E., Zanda, M., Mergaert, P., and Ferguson, G. P. 2011. Protection of Sinorhizobium against host cysteine-rich antimicrobial peptides is critical for symbiosis. PLoS Biol. 9:e1001169.

Haarer, B. K., and Amberg, D. C. 2004. Old yellow enzyme protects the actin cytoskeleton from oxidative stress. Mol. Biol. Cell 15:4522 4531

Hausinger, R. P. 2019. New metal cofactors and recent metallocofactor insights. Curr. Opin. Struct. Biol. 59:1-8.

Herridge, D. F., Peoples, M. B., and Boddey, R. M. 2008. Global inputs of biological nitrogen fixation in agricultural systems. Plant Soil 311: 1-18.

Hirsch, A. M., Bang, M., and Ausubel, F. M. 1983. Ultrastructural analysis of ineffective alfalfa nodules formed by nif:Tn5 mutants of Rhizobium meliloti. J. Bacteriol. 155:367-380.

Horchani, F., Prévot, M., Boscari, A., Evangelisti, E., Meilhoc, E., Bruand, C., Raymond, P., Boncompagni, E., Aschi-Smiti, S., Puppo, A., and Brouquisse, R. 2011. Both plant and bacterial nitrate reductases contribute to nitric oxide production in Medicago truncatula nitrogen-fixing nodules. Plant Physiol. 155:1023-1036.

Hosie, A. H., Allaway, D., Galloway, C. S., Dunsby, H. A., and Poole, P. S. 2002. Rhizobium leguminosarum has a second general amino acid permease with unusually broad substrate specificity and high similarity to branched-chain amino acid transporters (Bra/LIV) of the ABC family. J. Bacteriol. 184:4071-4080.

Kazmierczak, T., Nagymihály, M., Lamouche, F., Barrière, Q., Guefrachi, I., Alunni, B., Ouadghiri, M., Ibijbijen, J., Kondorosi, E.' Mergaert, P., and Gruber, V. 2017. Specific host-responsive associations between Medicago truncatula accessions and Sinorhizobium strains. Mol. Plant-Microbe Interact. 30:399-409.

Kelly, R. T., Page, J. S., Luo, Q., Moore, R. J., Orton, D. J., Tang, K., and Smith, R. D. 2006. Chemically etched open tubular and monolithic emitters for nanoelectrospray ionization mass spectrometry. Anal. Chem. 78:7796-7801.

Kim, S., Gupta, N., and Pevzner, P. A. 2008. Spectral probabilities and generating functions of tandem mass spectra: A strike against decoy databases. J. Proteome Res. 7:3354-3363.

Kim, S., and Pevzner, P. 2012. MS-GF+: Universal database search tool for mass spectrometry. In: 8th Ann. U.S. HUPO Conf. (US-HUPO), San Francisco, CA, U.S.A.

Kitzing, K., Fitzpatrick, T. B., Wilken, C., Sawa, J., Bourenkov, G. P., Macheroux, P., and Clausen, T. 2005. The 1.3 A crystal structure of the flavoprotein YqjM reveals a novel class of Old Yellow Enzymes. J. Biol. Chem. 280:27904-27913.

Koch, M., Delmotte, N., Rehrauer, H., Vorholt, J. A., Pessi, G., and Hennecke, H. 2010. Rhizobial adaptation to hosts, a new facet in the legume root-nodule symbiosis. Mol. Plant-Microbe Interact. 23:784-790.

Larrainzar, E., Wienkoop, S., Weckwerth, W., Ladrera, R., Arrese-Igor, C., and González, E. M. 2007. Medicago truncatula root nodule proteome analysis reveals differential plant and bacteroid responses to drought stress. Plant Physiol. 144:1495-1507.

Ledbetter, R. N., Garcia Costas, A. M., Lubner, C. E., Mulder, D. W. Tokmina-Lukaszewska, M., Artz, J. H., Patterson, A., Magnuson, T. S., Jay, Z. J., Duan, H. D., Miller, J., Plunkett, M. H., Hoben, J. P., Barney, B. M., Carlson, R. P., Miller, A. F., Bothner, B., King, P. W., Peters, J. W., and Seefeldt, L. C. 2017. The electron bifurcating FixABCX protein complex from Azotobacter vinelandii: Generation of low-potential reducing equivalents for nitrogenase catalysis. Biochemistry 56:4177-4190.

LeVier, K., Phillips, R. W., Grippe, V. K., Roop, R. M., 2nd, and Walker, G. C. 2000. Similar requirements of a plant symbiont and a mammalian pathogen for prolonged intracellular survival. Science 287:2492-2493.

Limpens, E., Moling, S., Hooiveld, G., Pereira, P. A., Bisseling, T., Becker, J. D., and Küster, H. 2013. Cell- and tissue-specific transcriptome analyses of Medicago truncatula root nodules. PLoS One 8:e64377.

Lin, D. X., Tang, H., Wang, E. T., and Chen, W. X. 2009. An ABC transporter is required for alkaline stress and potassium transport regulation in Sinorhizobium meliloti. FEMS Microbiol. Lett. 293:35-41. 
Lodwig, E. M., Hosie, A. H., Bourdès, A., Findlay, K., Allaway, D., Karunakaran, R., Downie, J. A., and Poole, P. S. 2003. Amino-acid cycling drives nitrogen fixation in the legume-Rhizobium symbiosis. Nature 422:722-726.

Lucas, S., Han, J., Lapidus, A., Cheng, J.-F., Goodwin, L., Pitluck, S., Peters, L., Mikhailova, N., Daligault, H., Han, C., Tapia, R., Land, M., Hauser, L., Kyrpides, N., Ivanova, N., Pagani, I., Brilli, M., Bazzicalupo, M., Mengoni, A., Biondi, E., and Woyke, T. 2012a. Complete sequence of plasmid 1 of Sinorhizobium meliloti BL225C. U.S. Department of Energy Joint Genome Institute, Berkeley, CA, U.S.A.

Lucas, S., Han, J., Lapidus, A., Cheng, J.-F., Goodwin, L., Pitluck, S., Peters, L., Mikhailova, N., Held, B., Detter, J. C., Han, C., Tapia, R., Land, M., Hauser, L., Kyrpides, N., Ivanova, N., Pagani, I., Brau, L., Yates, R., O'Hara, G., Rui, T., Howieson, J., Reeve, W., and Woyke, T. 2012b. Improved high-quality draft sequence of Rhizobium leguminosarum bv. trifolii WSM2012. U.S. Department of Energy Joint Genome Institute, Berkeley, CA, U.S.A.

Ma, W., Charles, T. C., and Glick, B. R. 2004. Expression of an exogenous 1-aminocyclopropane-1-carboxylate deaminase gene in Sinorhizobium meliloti increases its ability to nodulate alfalfa. Appl. Environ. Microbiol. 70:5891-5897.

Ma, W., Guinel, F. C., and Glick, B. R. 2003. Rhizobium leguminosarum biovar viciae 1-aminocyclopropane-1-carboxylate deaminase promotes nodulation of pea plants. Appl. Environ. Microbiol. 69:4396-4402.

Mandon, K., Osterås, M., Boncompagni, E., Trinchant, J. C., Spennato, G., Poggi, M. C., and Le Rudulier, D. 2003. The Sinorhizobium meliloti glycine betaine biosynthetic genes (betlCBA) are induced by choline and highly expressed in bacteroids. Mol. Plant-Microbe Interact. 16:709-719.

Marshall, S. J., Krause, D., Blencowe, D. K., and White, G. F. 2004. Characterization of glycerol trinitrate reductase (NerA) and the catalytic role of active-site residues. J. Bacteriol. 186:1802-1810.

Marx, H., Minogue, C. E., Jayaraman, D., Richards, A. L., Kwiecien, N. W., Siahpirani, A. F., Rajasekar, S., Maeda, J., Garcia, K., Del Valle-Echevarria, A. R., Volkening, J. D., Westphall, M. S., Roy, S., Sussman, M. R., Ané, J. M., and Coon, J. J. 2016. A proteomic atlas of the legume Medicago truncatula and its nitrogen-fixing endosymbiont Sinorhizobium meliloti. Nat. Biotechnol. 34:1198-1205.

Maunoury, N., Redondo-Nieto, M., Bourcy, M., Van de Velde, W., Alunni, B., Laporte, P., Durand, P., Agier, N., Marisa, L., Vaubert, D., Delacroix, H., Duc, G., Ratet, P., Aggerbeck, L., Kondorosi, E., and Mergaert, P. 2010. Differentiation of symbiotic cells and endosymbionts in Medicago truncatula nodulation are coupled to two transcriptome-switches. PLoS One 5:e9519.

McDermott, T. R., and Kahn, M. L. 1992. Cloning and mutagenesis of the Rhizobium meliloti isocitrate dehydrogenase gene. J. Bacteriol. 174:4790-4797.

Meilhoc, E., Cam, Y., Skapski, A., and Bruand, C. 2010. The response to nitric oxide of the nitrogen-fixing symbiont Sinorhizobium meliloti. Mol. Plant-Microbe Interact. 23:748-759.

Moreau, S., Verdenaud, M., Ott, T., Letort, S., de Billy, F., Niebel, A., Gouzy, J., de Carvalho-Niebel, F., and Gamas, P. 2011. Transcription reprogramming during root nodule development in Medicago truncatula. PLoS One 6:e16463.

Natera, S. H., Guerreiro, N., and Djordjevic, M. A. 2000. Proteome analysis of differentially displayed proteins as a tool for the investigation of symbiosis. Mol. Plant-Microbe Interact. 13:995-1009.

Nicora, C. D., Anderson, B. J., Callister, S. J., Norbeck, A. D., Purvine, S. O., Jansson, J. K., Mason, O. U., David, M. M., Jurelevicius, D., Smith, R. D., and Lipton, M. S. 2013. Amino acid treatment enhances protein recovery from sediment and soils for metaproteomic studies. Proteomics 13:2776-2785.

Ogden, A. J., Gargouri, M., Park, J., Gang, D. R., and Kahn, M. L. 2017. Integrated analysis of zone-specific protein and metabolite profiles within nitrogen-fixing Medicago truncatula-Sinorhizobium medicae nodules. PLoS One 12:e0180894.

Oldroyd, G. E., Engstrom, E. M., and Long, S. R. 2001. Ethylene inhibits the Nod factor signal transduction pathway of Medicago truncatula. Plant Cell 13:1835-1849.

Oldroyd, G. E., Murray, J. D., Poole, P. S., and Downie, J. A. 2011. The rules of engagement in the legume-rhizobial symbiosis. Annu. Rev. Genet. 45:119-144

Patriarca, E. J., Tatè, R., and Iaccarino, M. 2002. Key role of bacterial $\mathrm{NH}_{4}{ }^{+}$metabolism in Rhizobium-plant symbiosis. Microbiol. Mol. Biol. Rev. 66:203-222.

Pham, T. V., and Jimenez, C. R. 2012. An accurate paired sample test for count data. Bioinformatics 28:i596-i602.
Pickering, B. S., and Oresnik, I. J. 2008. Formate-dependent autotrophic growth in Sinorhizobium meliloti. J. Bacteriol. 190:6409-6418.

Poysti, N. J., Loewen, E. D. M., Wang, Z., and Oresnik, I. J. 2007. Sinorhizobium meliloti pSymB carries genes necessary for arabinose transport and catabolism. Microbiol. Read. 153:727-736.

Prell, J., Bourdès, A., Kumar, S., Lodwig, E., Hosie, A., Kinghorn, S., White, J., and Poole, P. 2010. Role of symbiotic auxotrophy in the Rhizobium-legume symbioses. PLoS One 5:e13933.

Prell, J., White, J. P., Bourdes, A., Bunnewell, S., Bongaerts, R. J., and Poole, P. S. 2009. Legumes regulate Rhizobium bacteroid development and persistence by the supply of branched-chain amino acids. Proc. Natl. Acad. Sci. U.S.A. 106:12477-12482.

R Core Team. 2008. R: A Language and Environment for Statistical computing. R Foundation for Statistical Computing, Vienna, Austria.

Reeve, W., Chain, P., O’Hara, G., Ardley, J., Nandesena, K., Bräu, L., Tiwari, R., Malfatti, S., Kiss, H., Lapidus, A., Copeland, A., Nolan, M., Land, M., Hauser, L., Chang, Y. J., Ivanova, N., Mavromatis, K., Markowitz, V., Kyrpides, N., Gollagher, M., Yates, R., Dilworth, M., and Howieson, J. 2010. Complete genome sequence of the Medicago microsymbiont Ensifer (Sinorhizobium) medicae strain WSM419. Stand. Genomic Sci. 2:77-86.

Resendis-Antonio, O., Hernández, M., Mora, Y., and Encarnación, S. 2012. Functional modules, structural topology, and optimal activity in metabolic networks. PLOS Comput. Biol. 8:e1002720.

Roberts, A. V. 2007. The use of bead beating to prepare suspensions of nuclei for flow cytometry from fresh leaves, herbarium leaves, petals and pollen. Cytometry A 71A:1039-1044.

Ronson, C. W., and Primrose, S. B. 1979. Effect of glucose on polyol metabolism by Rhizobium trifolii. J. Bacteriol. 139:1075-1078.

Roux, B., Rodde, N., Jardinaud, M. F., Timmers, T., Sauviac, L., Cottret, L., Carrère, S., Sallet, E., Courcelle, E., Moreau, S., Debellé, F., Capela, D., de Carvalho-Niebel, F., Gouzy, J., Bruand, C., and Gamas, P. 2014. An integrated analysis of plant and bacterial gene expression in symbiotic root nodules using laser-capture microdissection coupled to RNA sequencing. Plant J. 77:817-837.

Salavati, A., Khatoon, A., Nanjo, Y., and Komatsu, S. 2012. Analysis of proteomic changes in roots of soybean seedlings during recovery after flooding. J. Proteomics 75:878-893.

Sambrook, J., Fritsch, E. F., and Maniatis, T. 1989. Molecular Cloning: A Laboratory Manual, 2nd ed. Cold Spring Harbor Laboratory Press, Cold Spring Harbor, NY, U.S.A.

Sauviac, L., Philippe, H., Phok, K., and Bruand, C. 2007. An extracytoplasmic function sigma factor acts as a general stress response regulator in Sinorhizobium meliloti. J. Bacteriol. 189:4204-4216.

Schenkluhn, L., Hohnjec, N., Niehaus, K., Schmitz, U., and Colditz, F. 2010. Differential gel electrophoresis (DIGE) to quantitatively monitor early symbiosis- and pathogenesis-induced changes of the Medicago truncatula root proteome. J. Proteomics 73:753-768.

Simsek, S., Ojanen-Reuhs, T., Stephens, S. B., and Reuhs, B. L. 2007. Strain-ecotype specificity in Sinorhizobium meliloti-Medicago truncatula symbiosis is correlated to succinoglycan oligosaccharide structure. J. Bacteriol. 189:7733-7740.

Skorupska, A., Janczarek, M., Marczak, M., Mazur, A., and Król, J. 2006. Rhizobial exopolysaccharides: Genetic control and symbiotic functions. Microb. Cell Fact. 5:7.

Smith, S. L., and Long, S. R. 1998. Requirements for syrM and nodD Genes in the Nodulation of Medicago truncatula by Rhizobium meliloti 1021. Mol. Plant-Microbe Interact. 11:937-940.

Sobrero, P., Schlüter, J. P., Lanner, U., Schlosser, A., Becker, A., and Valverde, C. 2012. Quantitative proteomic analysis of the Hfq-regulon in Sinorhizobium meliloti 2011. PLoS One 7:e48494.

Somerville, J. E., and Kahn, M. L. 1983. Cloning of the glutamine synthetase I gene from Rhizobium meliloti. J. Bacteriol. 156:168-176.

Stacey, G., Libault, M., Brechenmacher, L., Wan, J., and May, G. D. 2006. Genetics and functional genomics of legume nodulation. Curr. Opin. Plant Biol. 9:110-121.

Streeter, J. G. 1980. Carbohydrates in soybean Nodules: II. DISTRIBUTION OF COMPOUNDS IN SEEDLINGS DURING THE ONSET OF NITROGEN FIXATION. Plant Physiol. 66:471-476.

Sugawara, M., Epstein, B., Badgley, B. D., Unno, T., Xu, L., Reese, J., Gyaneshwar, P., Denny, R., Mudge, J., Bharti, A. K., Farmer, A. D. May, G. D., Woodward, J. E., Médigue, C., Vallenet, D., Lajus, A., Rouy, Z., Martinez-Vaz, B., Tiffin, P., Young, N. D., and Sadowsky, M. J. 2013. Comparative genomics of the core and accessory genomes of 48 Sinorhizobium strains comprising five genospecies. Genome Biol. 14:R17.

Tatsukami, Y., Nambu, M., Morisaka, H., Kuroda, K., and Ueda, M. 2013. Disclosure of the differences of Mesorhizobium loti under the 
free-living and symbiotic conditions by comparative proteome analysis without bacteroid isolation. BMC Microbiol. 13:180.

Terpolilli, J. J., Hood, G. A., and Poole, P. S. 2012. What determines the efficiency of N(2)-fixing Rhizobium-legume symbioses? Adv. Microb. Physiol. 60:325-389.

Terpolilli, J. J., O'Hara, G. W., Tiwari, R. P., Dilworth, M. J., and Howieson, J. G. 2008. The model legume Medicago truncatula A17 is poorly matched for $\mathrm{N} 2$ fixation with the sequenced microsymbiont Sinorhizobium meliloti 1021. New Phytol. 179:62-66.

Udvardi, M., and Poole, P. S. 2013. Transport and metabolism in legume-rhizobia symbioses. Annu. Rev. Plant Biol. 64:781-805.

Van de Velde, W., Zehirov, G., Szatmari, A., Debreczeny, M., Ishihara, H., Kevei, Z., Farkas, A., Mikulass, K., Nagy, A., Tiricz, H., SatiatJeunemaître, B., Alunni, B., Bourge, M., Kucho, K., Abe, M., Kereszt, A., Maroti, G., Uchiumi, T., Kondorosi, E., and Mergaert, P. 2010. Plant peptides govern terminal differentiation of bacteria in symbiosis. Science 327:1122-1126.

Volkening, J. D., Bailey, D. J., Rose, C. M., Grimsrud, P. A., HowesPodoll, M., Venkateshwaran, M., Westphall, M. S., Ané, J. M., Coon, J. J., and Sussman, M. R. 2012. A proteogenomic survey of the Medicago truncatula genome. Mol. Cell. Proteomics 11:933-944.

Wang, Y., Yang, F., Gritsenko, M. A., Wang, Y., Clauss, T., Liu, T., Shen, Y., Monroe, M. E., Lopez-Ferrer, D., Reno, T., Moore, R. J., Klemke, R. L., Camp, D. G., 2nd, and Smith, R. D. 2011. Reversed-phase chromatography with multiple fraction concatenation strategy for proteome profiling of human MCF10A cells. Proteomics 11:2019-2026.

White, G. F., Snape, J. R., and Nicklin, S. 1996. Biodegradation of glycerol trinitrate and pentaerythritol tetranitrate by Agrobacterium radiobacter. Appl. Environ. Microbiol. 62:637-642.

Williams, R. E., and Bruce, N. C. 2002. 'New uses for an Old Enzyme'-the Old Yellow Enzyme family of flavoenzymes. Microbiol. Read. 148:1607-1614.

Willis, L. B., and Walker, G. C. 1999. A novel Sinorhizobium meliloti operon encodes an alpha-glucosidase and a periplasmic-binding-proteindependent transport system for alpha-glucosides. J. Bacteriol. 181:41764184.

Young, N. D., Debellé, F., Oldroyd, G. E., Geurts, R., Cannon, S. B., Udvardi, M. K., Benedito, V. A., Mayer, K. F., Gouzy, J., Schoof, H., Van de Peer, Y., Proost, S., Cook, D. R., Meyers, B. C., Spannagl, M., Cheung, F., De Mita, S., Krishnakumar, V., Gundlach, H., Zhou, S., Mudge, J., Bharti, A. K., Murray, J. D., Naoumkina, M. A., Rosen, B., Silverstein, K. A., Tang, H., Rombauts, S., Zhao, P. X., Zhou, P.,
Barbe, V., Bardou, P., Bechner, M., Bellec, A., Berger, A., Bergès, H., Bidwell, S., Bisseling, T., Choisne, N., Couloux, A., Denny, R., Deshpande, S., Dai, X., Doyle, J. J., Dudez, A. M., Farmer, A. D., Fouteau, S., Franken, C., Gibelin, C., Gish, J., Goldstein, S., González, A. J., Green, P. J., Hallab, A., Hartog, M., Hua, A., Humphray, S. J., Jeong, D. H., Jing, Y., Jöcker, A., Kenton, S. M., Kim, D. J., Klee, K., Lai, H., Lang, C., Lin, S., Macmil, S. L., Magdelenat, G., Matthews, L., McCorrison, J., Monaghan, E. L., Mun, J. H., Najar, F. Z., Nicholson, C., Noirot, C., O’Bleness, M., Paule, C. R., Poulain, J., Prion, F., Qin, B., Qu, C., Retzel, E. F., Riddle, C., Sallet, E., Samain, S., Samson, N., Sanders, I., Saurat, O., Scarpelli, C., Schiex, T., Segurens, B., Severin, A. J., Sherrier, D. J., Shi, R., Sims, S., Singer, S. R., Sinharoy, S., Sterck, L., Viollet, A., Wang, B. B., Wang, K., Wang, M., Wang, X., Warfsmann, J., Weissenbach, J., White, D. D., White, J. D., Wiley, G. B., Wincker, P., Xing, Y., Yang, L., Yao, Z., Ying, F., Zhai, J., Zhou, L., Zuber, A., Dénarié, J., Dixon, R. A., May, G. D., Schwartz, D. C., Rogers, J., Quétier, F., Town, C. D., and Roe, B. A. 2011. The Medicago genome provides insight into the evolution of rhizobial symbioses. Nature 480:520-524.

Yuan, Z. C., Zaheer, R., and Finan, T. M. 2006. Regulation and properties of PstSCAB, a high-affinity, high-velocity phosphate transpor system of Sinorhizobium meliloti. J. Bacteriol. 188:1089-1102.

Yurgel, S. N., and Kahn, M. L. 2004. Dicarboxylate transport by rhizobia. FEMS Microbiol. Rev. 28:489-501.

Yurgel, S. N., and Kahn, M. L. 2005. Sinorhizobium meliloti dctA mutants with partial ability to transport dicarboxylic acids. J. Bacteriol. 187:1161-1172.

Yurgel, S. N., and Kahn, M. L. 2008. A mutant GlnD nitrogen sensor protein leads to a nitrogen-fixing but ineffective Sinorhizobium meliloti symbiosis with alfalfa. Proc. Natl. Acad. Sci. U.S.A. 105:18958 18963.

Yurgel, S. N., Rice, J., and Kahn, M. L. 2012. Nitrogen metabolism in Sinorhizobium meliloti-alfalfa symbiosis: Dissecting the role of GlnD and PII proteins. Mol. Plant-Microbe Interact. 25:355-362.

Yurgel, S. N., Rice, J., Mulder, M., and Kahn, M. L. 2010. GlnB/GlnK PII proteins and regulation of the Sinorhizobium meliloti Rm1021 nitrogen stress response and symbiotic function. J. Bacteriol. 192 2473-2481.

Zhang, Y., Aono, T., Poole, P., and Finan, T. M. 2012. NAD $(\mathrm{P})^{+}$-malic enzyme mutants of Sinorhizobium sp. strain NGR234, but not Azorhizobium caulinodans ORS571, maintain symbiotic $\mathrm{N}_{2}$ fixation capabilities. Appl. Environ. Microbiol. 78:2803-2812. 